Florida International University FIU Digital Commons

$10-7-1994$

\title{
The effect of familiarity of task and choice on the functional performance of young and old adults
}

Anne E. Dickerson

Florida International University

DOI: $10.25148 /$ etd.FI14062281

Follow this and additional works at: https://digitalcommons.fiu.edu/etd

Part of the Psychology Commons

\section{Recommended Citation}

Dickerson, Anne E., "The effect of familiarity of task and choice on the functional performance of young and old adults" (1994). FIU Electronic Theses and Dissertations. 2809.

https://digitalcommons.fiu.edu/etd/2809 
FLORIDA INTERNATIONAL UNIVERSITY

Miami, Florida

THE EFFECT OF FAMILIARITY OF TASK AND CHOICE ON THE FUNCTIONAL PERFORMANCE OF YOUNG AND OLD ADULTS

A dissertation submitted in partial satisfaction of the requirements for the degree of DOCTOR OF PHILOSOPHY

IN

PSYCHOLOGY

by

Anne Elizabeth Dickerson

1994 
To: Dean Arthur W. Herriott College of Arts and Sciences

This dissertation, written by Anne E. Dickerson, and entitled The Effect of Familiarity of Task and Choice on the Functional Performance of Young and Old Adults, having been approved in respect to style and intellectual content, is referred to you for judgement.

We have all read this dissertation and recommend that it be approved.

Paul Foos

William Kurtines

Paulette Johnson

Mary Levitt, Major Professor

Date of Defense: October 7, 1994.

The dissertation of Anne E. Dickerson is approved.

Dean Arthur W. Herriott College of Arts and Sciences

Dr. Richard L. Campbell Dean of Graduate Studies

Florida International University, 1994 
CCOPYRIGHT 1994 by Anne E. Dickerson

All rights reserved. 
I dedicate this dissertation to my husband Rick. Without his loving support and loyal dedication to me and our sons, the completion of this work would have never been possible. This work is as much his as it is mine. 


\section{ACKNOWLEDGMENTS}

I wish to thank the members of my committee, Dr. Paul Foos,

Dr. Paulette Johnson, and Dr. William Kurtines for their helpful comments and support during the process of this work.

A very special thanks goes to my major professor, Dr. Mary Levitt, for her continued and important support and assistance on a long distance project that survived a hurricane, relocation, and two babies.

Another special thanks goes to Dr. Anne Fisher who allowed me to use her assessment tool, assisted me with data collection and analysis, helped with the conception of the study, and critiqued my thoughts and ideas during the entire process. Truly without Dr. Fisher's help, support, and friendship, this work would never have been completed. With her permission, I have some copywritted material from her assessment tool, the Assessment of Motor and Process Skills, in this work.

I am also grateful to the American Occupational Therapy Foundation for funding a grant to complete this study. Without their finanical support, this work would have not only been delayed in completion, but would have not been as vigorous a study. 


\section{ABSTRACT OF THE DISSERTATION}

THE EFFECT OF FAMILIARITY OF TASK AND CHOICE ON THE FUNCTIONAL PERFORMANCE OF YOUNG AND OLD ADULTS

by

\section{Anne Elizabeth Dickerson}

Florida International University, 1994

Professor Mary J. Levitt, Major Professor

An experiment was conducted to compare the functional performance of young and old adults on familiar and unfamiliar tasks under two conditions of perceived control. Specifically, the relation between age and motor and process skills was examined. The familiar tasks were simple cooking tasks, whereas the unfamiliar tasks were contrived, meaningless tasks developed for this study. Young and old did not differ in the ratings of the familiarity of the tasks, but results from two Age by Task by Choice ANOVAs demonstrated a significant age difference for motor and process skills under all conditions. For the process skill scale, there was also a significant main effect for choice. This suggests that older adults demonstrate age-related decline even with activities that take motivational, 
experiential, and ecological validity components into account. Results also support the concept that perceived control can improve performance, but not differentially for older adults; that is, young and old adults both demonstrated improved performance when given their choice of tasks. 


\section{TABLE OF CONTENTS}

CHAPTER

PAGE

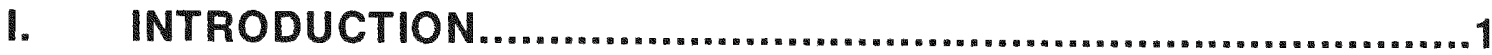

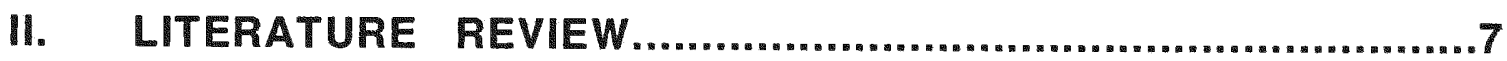

Motor Component...........................................................

Cognitive Component..................................................14

Variables That Minimize Age Differences................19

Choice as a Control Variable......................................43

Purpose of the Study................................................57

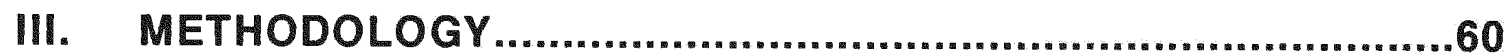

Subjects....................................................................60

Instrumentation...................................................61

Procedure...............................................................67

Design ........................................................................

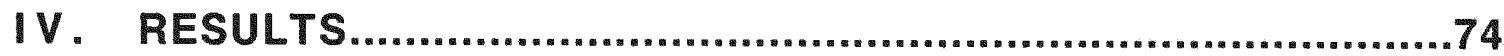

Rasch Measurement Model...........................................74

ANOVAs...................................................................

V. DISCUSSION..................................................................

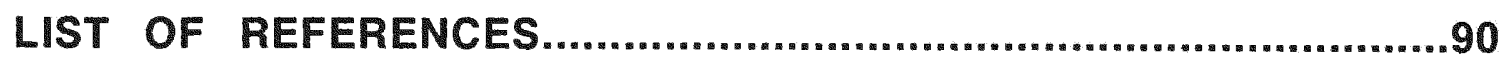

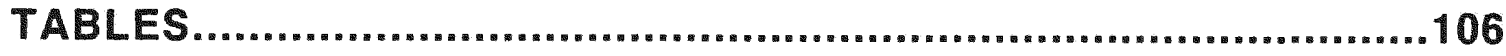

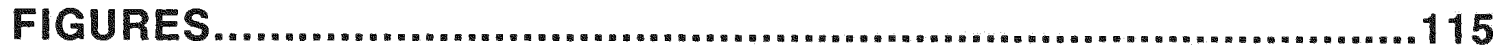

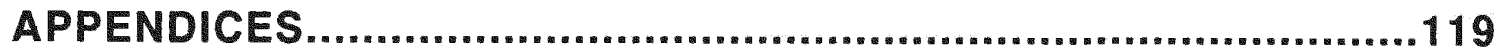

VITA 


\section{LIST OF TABLES}

1. Results of Familiar Task Survey 106

2. Number of Completed Chosen and Assigned Tasks Performed by Young and Old Adults.

3. Means and Standard Deviations for Familarity of Tasks for Young and Old Adults.

4. ANOVA Table for Familiarity of Task.......................................109

5. Rasch Measurement Model Fit Statistics for Tasks.................110

6. Rasch Measurement Model Fit Statistics for Raters.................111

7. Means and Standard Deviations of Motor and Process Scores of Subjects Under All Conditions.

8. ANOVA Table for Motor Scale.

9. ANOVA Table for Process Scale. 


\section{LIST OF FIGURES}

1. Scatterplot of motor skill scores by age.................................116

2. Scatterplot of process skill scores by age.............................118 


\section{LIST OF APPENDICES}

A. Motor and Process Skill Items Defined.........................................119

B. Score Sheet for Assessment and Sample of Skill Item...........125

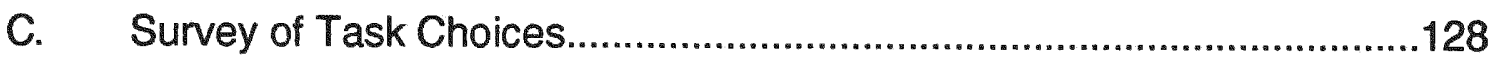

D. Written Directions for Familiar Tasks......................................129

E. Written Directions for Unfamiliar Tasks.................................132

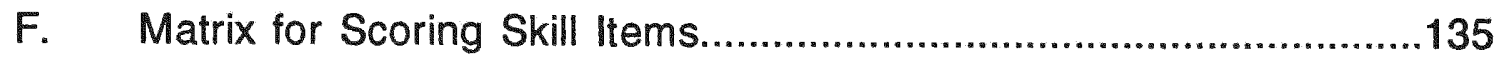




\section{Chapter 1: Introduction}

A large amount of research has been done to identify the effects of aging on motor and cognitive skills. Frequently, research findings reveal substantial age-related declines in performance when comparing young and old adults. However, researchers now recognize that although physiological and cognitive changes with age do limit performance, it is difficult to distinguish the changes due to aging per se and those due to differing amounts of physical activity, motivation, experience, occurrence of disease, and societal expectations (Spirduso \& MacRae, 1990). Specifically, Spirduso and MacRae (1990) addressed the need to document and understand human strength and power capabilities in the older decades. They discussed the fact that although motor task performance declines with age, some abilities are maintained in the older active adult. Additionally, Salthouse (1990) differentiated between cognitive abilities and cognitive competence, emphasizing that how the older adult performs in traditional laboratory studies and psychometric experiments does not adequately reflect the older adult's performance in occupational and daily living activities. He discusses four general categories of interpretation that may explain 
the discrepancies between cognitive abilities and cognitive competence including: 1) the type of cognitive ability being assessed (e.g., fluid versus crystallized knowledge), 2) the representativeness of the behavioral observation or sample of individuals, 3) the sensitivity of the measurement or evaluation and 4) the amount of relevant experience.

Further, it has been suggested by Kausler (1990) and others (Perlmuter \& Monty, 1989; Perlmuter, Monty, \& Chan, 1986) that, although studies have indicated that there is no age difference in the functional relationship between extrinsic motivation and performance scores, the issue of control (e.g., choices over content of tasks to be performed) may affect this functional relationship. Young adults have been found to perform at a higher level when they have control over the content of the task to be performed, but the effect of this control has not been explored thoroughly with the older adult, because most laboratory studies do not allow the opportunity for control by subjects (Kausler, 1990). Therefore, this study compared the motor and cognitive performance of young and old adults doing tasks with which they were familiar and unfamiliar under conditions of control and noncontrol. 
This study was an expansion of an earlier study (Dickerson, 1990) in which young and old adults were compared performing two types of tasks, normal activities of daily living (ADL) which were meaningful, familiar, and well practiced, and a contrived task that was relatively unfamiliar. The results suggest that older adults demonstrate age-related decline with tasks even when those tasks are familiar, practiced and ecologically valid. However, a limitation of this study was the lack of control (i.e., choice of the contrived activity) in the unfamiliar task. This present study addressed this limitation by creating conditions of choice for both the familiar and unfamiliar tasks. Further, this study was strengthened by the fact that the unfamiliar tasks were meaningless as well as unfamiliar to subjects.

This study is based on the assumption that older individuals are more likely to have some motor and process skill deficits in traditional psychometric tests. However, when couched in meaningful and practiced tasks, the older adults can compensate for inefficiencies or deficits and perform proficiently, particularly when offered the choice of tasks.

As with the previous study, functional performance was 
utilized as the context of study. Using functional performance measures is important in aging research for two major reasons. First, there is the question of the external validity of traditional intelligence and other psychometric test instruments. Assessing individuals in natural settings will have greater generalizability in terms of their ability to process and perform tasks.

Second, functional performance evaluations are being recognized as superior to the self- or proxy-reports generally used to report physical functioning (Guralnik, Branch, Cummings, \& Curb, 1989; Rubenstein, Schairer, Wieland, \& Kane, 1984). Guralnik et al. underscore the importance of functional performance assessment in not only clinical geriatrics, but in aging research as well. The authors highlight the advantages of the performance report over self report as 1) having more face validity for the task, as it is not compromised by variations in interpretations, 2) having greater reproducibility or reliability, 3) having greater sensitivity to changes in functioning, 4) being influenced less by culture, language, and education, and 5) being influenced less by poor cognitive functioning. Rubenstein et al.'s study on a group of hospitalized elderly demonstrated that the patients tended to overstate their 
functional abilities whereas significant others and nursing staff tended to understate their abilities. Requiring an individual to perform, therefore, provides the truest picture of function.

This study used the Assessment of Motor and Process Skills (AMPS) to measure the performance of the subjects during task performance. The AMPS is an observational assessment that simultaneously evaluates the underlying motor and process skills and their impact on the ability of the individual to perform functional tasks of daily living (Fisher, 1989, 1993). Motor skills are evaluated by observing the posture, mobility, coordination, and strength of the individual through movement of their body and objects. Process skills are evaluated by observing the attentional, ideational, organizational, and adaptive processes of the individual by how they organize their actions performed enroute to task completion (Fisher, 1989, 1993). The measurement model used with AMPS allows for variation in rater biases, tasks challenge, and item difficulty.

The AMPS was used to assess young and old adults' process and motor skills while performing eight activities. Four tasks were meaningful, practiced, and familiar and four were contrived, 
meaningless, and unfamiliar. Each subject was assigned two familiar and two unfamiliar tasks to complete and selected the other four tasks (two familiar and two unfamiliar) from a list of four different familiar tasks and four different unfamiliar tasks. The objective of the study was to describe age-related performance differences with familiar and unfamiliar tasks when experiential and control factors are taken into account. 


\section{Chapter 2: Review of the Literature}

\section{Motor Component}

Most will agree that, as the body ages, the physical capacities of an individual decline. There are losses of muscle units, changes in metabolism of those remaining, and higher thresholds for neural excitation of muscle with age. Along with local limitations in muscular performance, there is an overall decrease in capacity with age (Welford, 1984). When investigating movement planning processes, Stelmach, Goggin, and Garcia-Colera (1986) suggested that older adults were slower in reaction time due in part to the processes involved in specifying movement dimensions. That is, if older adults cannot prepare a response in advance, they are slower and less efficient when organizing a response. In a more recent study, Amrhein, Stelmach, and Goggin (1991) found that older adults exhibit functional changes in movement preparation processes when compared to young adults. Specifically, they found that although older adults are slower, the manner in which they initially prepare a movement plan and how they use information about precue probability and stimulus uncertainty is similar to young adults. However, study results showed that young and old individuals 
differed in their maintenance of movement preparation for direction. That is, the older adults could not maintain direction preparation when required.

There is also evidence that older adults have impairment in postural mechanisms (i.e., balance control). Woollacott, ShumwayCook, and Nashner (1986) demonstrated that older people had impaired postural control under conditions of reduced or conflicting sensory information when compared to younger adults. Stelmach, Teasdale, DiFabio, and Phillips (1989) also found that the elderly, although they have reflexive responses similar to young adults, were at a disadvantage when posture was under the control of slower and more voluntary mechanisms. To examine these slower integrative mechanisms further, Teasdale, Stelmach, and Breunig (1991) designed an experiment to determine if a reduction of visual, somatosensory (proprioception), or both visual and somatosensory input disrupted postural control differentially in young and old adults. Their results indicated that disruption of only one of the sensory inputs did not substantially influence the older adults's balance. However, when both the visual input was gone and proprioceptive information altered, the older adults' balance control 
was significantly affected.

Specifically, proprioceptive feedback seems to be affected by age. Meeuwsen, Sawicki, and Stelmach (1993) investigated the acuity of perceived foot position with young and old adults.

Compared to the young, older adults were slower and less accurate in identifying afferent proprioceptive signals from the ankle joint. However, with repetition, the older adults did improve their speed of information processing, although not to the level of the young adults. Another study by Stelmach, Amrhein, and Goggin (1988) suggests that specific aging deficits are also present in bimanual coordination processes. This was confirmed in a more recent study (Light \& Spirduso, 1990) which examined the effects of age and movement complexity. Light and Spirduso found that reaction time increased as movement complexity increased and bilateral versus unilateral movement control appeared to be a significant movement complexity factor of response programming.

Other sources (Botwinick, 1984; Kausler, 1982; Levy, 1986) confirm the decrease in each of the sensory modalities; such decreasing capacity means increased demands on the elderly person engaging in functional performance. Although deficits in motor 
skills may be more observable during a task, deficits in process (cognitive) skills are harder to quantify; however, such process deficits could have an impact on the motor output and on task performance. In fact, Fisher (1989) emphasizes that deficits in balance, mobility, coordination, or strength place increased demand on the individual's adaptive capacities and process skills. If the motor and process skills are decreased, the individual is at risk for losing independence.

Most research evidence supports the finding that older adults are slower than young adults in every kind of function (e.g., reaction time) (Botwinick, 1984; Salthouse, 1985a, 1985b). In fact, it is a finding that is the most strongly substantiated and least disputed in the aging literature (Botwinick, 1984). However, the relationship between age and motor performance is not a simple one.

Specifically, the link between exercise and cognition cannot be overlooked. For example, Botwinick and Thompson (1968) demonstrated that when measuring reaction time, there was a significant difference between older adults and young adult athletes. However, there was not a significant difference in reaction time between older adults and young adult nonathletes. Botwinick and 
Thompson suggest that the amount of exercise may be more a cofunction of the central nervous system than an antecedent or cause of the slowdown.

In another study examining the link between exercise and reaction time, Baylor and Spirduso (1988) found that older women who were committed to regular aerobic exercise performed significantly better in reactive capacity than older women who had no regular exercise. They measured reaction time through fractionation of reaction time by electromyographical recording of the muscle into two components, premotor time (the central processing component) and contractile time (the peripheral component). Not only did they find large differences in the central processing component, but they also found that the women who were regularly exercising had better contractile times (the peripheral component).

Clarkson-Smith and Hartley (1989) presented correlational data that demonstrated a strong positive relationship between exercise and performance in three areas of cognition after statistically controlling for age, education, and vocabulary scores. Older adults who exercised vigorously performed significantly 
better than sedentary adults in reasoning, working memory, and reaction times. Acknowledging the fact that the data were only correlational, the researchers believe that the relationship of exercise with the cognitive variables was strong enough to suggest a causal relationship between exercise and cognition and to urge further research with longitudinal studies.

Strong evidence of the relationship between exercise and attention in older adults was demonstrated with a study by Hawkins, Kramer, and Capaldi (1992). In their first experiment they found age differences in two attentional tasks, a time-sharing task and an attentional flexibility task. In both tasks, young adults performed significantly better than the older adults. Then they examined the effects of mild aerobic exercise on the same two attentional tasks with older adults. Results demonstrated that the older adults who participated in a 10 week swimming program showed significant improvement in the dual-task processing tasks, but were equal in performance to the control group in the single-task. This study indicates that, even with a short-term program of exercise, there is a link between exercise and at least two different attentional processes in healthy older adults. 
Along the same lines, Spirduso (1980) reviewed studies

concerning physical fitness, aging, and psychomotor speed. Spirduso pointed out that studies tend to show that older physically active men are more like younger men than their aged counterparts. She suggested that health may be more related to performance than age. More recently, Spirduso and MacRae (1990) stated that motor performance becomes more variable with increasing age. They highlight data that support the contention that decline in motor performance is not strictly a function of age. For example, an individual's maximal oxygen uptake, which indicates a person's cardiorespiratory fitness, is affected by factors such as present level of training, age of onset of training, disease, and genetic profile. Further, muscular endurance can be maintained successfully in active older adults, although muscle strength may decline. Spirduso and MacRae also identified factors that minimize age differences in psychomotor speed including practice effects, predictability of target sets, physical fitness level, and effects of exercise. Their conclusion is that the present knowledge about the extent and nature of the interaction between age and the compatibility and complexity of stimuli and motor response is 
rudimentary and further research is necessary (Spirduso \& MacRae, 1990).

\section{Cognitive Component}

It is well documented that older adults have decreased speed in processing information and performing tasks. Studies indicate that older adults' cognitive systems organize information by the same principles as in young adults, but do it at a slower rate or less efficiently (Hess \& Slaughter, 1986a, 1986b; Puglisi, Park, Smith, \& Dudley, 1988; Simon \& Pouraghabagher, 1978; Salthouse \& Prill, 1987; Salthouse, 1985b). Results from two separate studies by Hess and Slaughter (1986a, 1986b), in which age differences were found, also support the contention that the cognitive system seems to spontaneously organize conceptual information in the same manner for young and old adults. Hess and Slaughter suggest that age-related processing capacity variations limit the older adults' ability to abstract and use conceptual information.

Salthouse and Somberg (1982) also support the idea that, with simple cognitive and perceptual skills, older adults go through the same processing operations as young adults, but at a slower rate. In their study, they had old and young subjects perform four simple 
tasks for 51 experimental sessions. Although there were still significant age differences (despite considerable improvement with practice), they found that both young and old used the same model of performance improvement and only differed in the absolute levels achieved.

In fact, recently Salthouse (1994) demonstrated that processing speed is a major factor in age-related differences in cognitive functioning. Two studies with 240 adults between 18 and 80 years of age were conducted to examine the relations between age, motor speed, perceptual speed, and three measures of cognitive functioning (study time, decision time, and decision accuracy). Results indicated that involvement of speed in relation to age and cognition was not restricted to timed or speeded measures of cognitive function. Perceptual speed was more important than motor speed as a mediator of age-cognitive relations and older adults were less accurate in their cognitive decisions because they were slower in executing relevant cognitive functions. Consistent with earlier studies including other cognitive tasks (Salthouse 1985b; 1987; 1993; Salthouse \& Prill, 1987), these findings support the interpretation that a slower speed of processing affects not only 
the quantity of cognitive performance, but also the quality, because the products of earlier operations may disintegrate before the later processing can compile the information to use it. Thus, although it is not clear what causes the relation between speed and age, nor if there are alternative explanations, there is convincing evidence that slower processing speed may function as a proximal mediator of relations between age and cognitive functioning (Salthouse, 1994). There is some evidence that speed and quality decrease during middle age, rather than just in old age. Wickens, Braune, and Stokes (1987) had subjects with age ranges from 20 to 65 perform a series of tasks designed to evaluate the effects of aging on the speed and capacity in processing. They found that information processing speed decreased monotonically and linearly throughout the life span. In another study, Fullerton (1988) investigated age differences in solving series problems requiring integration of new and old information. Scores of the middle aged subjects (ages 40-59) were significantly lower than scores of young subjects, both in their integration and inference, suggesting that deficits in the ability to manipulate items in the working memory may decline at a relatively early adult age. 
Studies have shown that older adults are vulnerable to the effects of divided attention (Crossley \& Hiscock, 1992; Ponds, Brouwer, \& Wolffelaar, 1988; McDowd, 1986; McDowd \& Birren, 1990; Mitchell \& Perlmuter, 1986; Plude \& Hoyer, 1986). This decline is thought to be due to the decreased processing capacity of older adults, especially when effortful rather than automatic memory operations are required (Craik \& Byrd, 1982; Crossley \& Hiscock, 1992; Hasher \& Zacks, 1979; Mitchell \& Perlmuter, 1986; Wright, 1981). Thus, when performing functional tasks that require one to attend to two or more actions, such as making coffee and toast, older adults may show deficits in skills when compared to young adults.

There are other cognitive processes, such as divergent thinking, deductive reasoning, and problem solving, that are being utilized while performing daily living tasks. The individual must organize information and use knowledge to accomplish the task. If a problem or error occurs during performance, the individual must use adaptive processes to anticipate, recognize, and/or correct the problem. Studies have demonstrated age differences in such processes. 
McCrae, Arenberg, and Costa (1987) studied divergent thinking (i.e., thinking characterized by the production of a number of acceptable solutions to a situation) in 825 men over a period of thirteen years. The comparison of cross sectional, longitudinal, and cross sequential results demonstrated strong evidence of a decline in divergent thinking abilities in late adulthood. Thus, the adaptive processing skills may be impaired with the older population. Other studies also show significant age-related declines in free recall when retrieval demands are increased (Macht \& Bushke, 1983), in deductive reasoning processes (Hartley, 1981), in hypothesis testing questions (Denney, 1985; Hartley \& Anderson, 1983), in encoding specificity (Puglisi et al, 1987), in utilizing encoding strategies (Till, 1985; Bruce \& Herman, 1986), in conceptual representation of complex stimuli (Hess \& Wallsten, 1987), and in answering inferential questions (Zacks, Hasher, Doren, Hamm, \& Attig, 1987).

Although many studies support the hypothesis of a generalized slowing of the central processes (Jacewicz \& Hartley, 1987), recent studies go further to specify that performance on nonverbal cognitive tasks involving psychomotor or spatial components show greater age differences than verbal tasks (Berg, Hertzog, \& Hunt, 
1982; Gaylord \& Marsh, 1975; Hale, Myerson, \& Wagstaff, 1987;

Puglisi, 1986; Salthouse, 1985b, 1987; Spirduso, 1980; Spirduso \& MacRae, 1990; Wickens et al., 1987). For example, Bruce and Herman (1986) compared young and old adults doing spatial memory tasks.

They found that older adults did not use effective encoding strategies and concluded that the older subjects needed more experience with the environment than young adults require to perform as accurately on spatial memory tasks. Because functional performance tasks include psychomotor processes and spatial skills, evaluating older adults in instrumental activities of daily living is important for detecting age-related differences in performance.

\section{Variables That May Minimize Age Differences}

Although there is not a consensus concerning the mechanisms underlying age-related differences, (i.e., whether there is a deficiency in temporal resources, energy, attentional resources, or working memory capacity), all of the cited studies have shown significant age-related differences in performance. Most would agree that the locus of these changes is some type of decrease in central processing which would affect the older adult's ability to sense and respond to the environment and contribute to the many 
cognitive aging differences. In fact, Cerella (1990) has proposed a model that explains age-related deficits at a neurological level. $\mathrm{He}$ suggests the cognitive processes are represented through signals that transverse through the brain in a neural network composed of links and nodes. Aging would be defined as the destructive process that breaks links at random over time. Thus, regardless of the cognitive processes, the "slowing" of aging would be the increased time for the signal to get around the broken links. Cerella argues, therefore, that explanations of age-related changes such as disuse, cautiousness, attentional deficits, etc. would not be needed because the data could be adequately predicted by the declines in neural substrate. Further, the implication is that changes in performance due to skill acquisition, strategy differences, and speed-accuracy tradeoff, etc. would operate in the old as in the young.

However, regardless of the underlying causes, it could be hypothesized that the older adult would demonstrate deficiencies and/or decreases in cognitive performance during functional daily living tasks. However, although these deficits are documented and assumed to be evident with the elderly, they may not be so readily apparent with tasks of daily living. Salthouse (1990) argues that 
the greatest challenge in the field of psychology and aging is to account for the discrepancy between the performance of older adults on psychometric cognitive measures and their successful functioning in their everyday situations. He suggests that this discrepancy can be accounted for if one differentiates between cognitive abilities and cognitive competence. Cognitive abilities are the individual's intellectual level, as measured by conventional tests of intelligence and cognitive functioning, whereas cognitive competence is the utilization of one's cognitive, interpersonal, and other abilities to adapt to a particular situation (Salthouse, 1990). Research studies have consistently found that older adults demonstrate poorer performance on measures of cognitive abilities than young adults, yet seem to be able to function well in their daily lives. It may be that even individuals with a low level of cognitive ability may achieve a high level of competence by maximizing his or her usage of available abilities in a specific situation (Salthouse, 1990). Salthouse proposes that the possible reasons for the discrepancy between cognitive abilities and cognitive competence includes the differences in the types of cognition assessed, the differential respresentativeness of subjects or behavioral 
observations, the different standards of evaluation, and the differing amounts of experience.

These and other issues have been identified in studies that highlight some of the limitations of the assumption that older adults will demonstrate deficiencies and/or decreases in cognitive performance during functional activities. These issues are interrelated and will be discussed in terms of methodology, ecological validity, practice, expertise, motivation, and control.

First, a study by Ratner, Schell, Crimmins, Mittelman, and Baldinelli (1987) compared the performance in prose recall between college students, noncollege young adults, and older adults. The results demonstrated that, despite similarities in age and verbal ability to the college students, the noncollege young adults performed more like the older adults than their college counterparts. Ratner et al. suggested that memory decline associated with age may result as much from cognitive demands as from biologically determined deterioration. This study casts doubts on studies that have used convenient college students in comparisons with older adults from less cognitively demanding environments.

Others have emphasized the greater variability of older adults 
compared to the range in a young age group (Baltes, 1987; Baltes \& Willis, 1982; Spirduso \& MacRae, 1990). Recently, to examine the assertion that there is increased variability with age, Morse (1993) reviewed studies in two aging journals. Calculating the coefficient of variability from data published in age difference studies between 1986 and 1990, Morse found evidence to support the assertion that there is increased variability with age for reaction time, memory, and fluid intelligence, but not for crystallized intelligence test scores. However, what differentiates those tasks on which older adults do demonstrate greater variability from young adults is not clarified. Therefore, because older adults' have varied experiences over a life-span or may be more likely to choose their own course of action, "known" age-related differences could possibly be artifacts of individual variation.

Another study exemplifies this possibility. Craik, Byrd, and Swanson (1987) compared memory performance of three elderly samples, which differed in terms of socioeconomic circumstances, levels of verbal ability, and activity level, and one young adult sample (undergraduate students). Their results indicated that, although there were age-related differences in some of the tests 
(paired associate and free and cued recall), the differences on the tasks were influenced by the characteristics of the elderly participants. The age differences observed were large, small, and nonexistent depending on the interactions among tasks, subjects, and materials. For example, age differences were most pronounced with the older adults who were of lower socioeconomic status, had lower verbal ability, and lower activity level, whereas the performance of the most able group of older adults (higher socioeconomic status, verbal ability, and activity level) did not differ from that of the young adult sample in at least one of the tasks. Further, performance reflected an interaction between the degree of support offered by the task and the ability level of the person performing the tasks. Participants from the least able older group performed poorly on recall until cues were provided at encoding and retrieval, whereas the other older groups could perform better with less support at either encoding or retrieval. Thus, Craik et al. argue that cognitive performance must be viewed in a contextual framework, that is, as a function of the particular tasks, participants, and materials used. In other words, cognitive theories must model the interactions between mental processes and relevant 
aspects of the environment (Craik, et al., 1987).

Along the same lines, Kirasic and Allen (1985) offered a framework for conceptualizing research with older adults. They compared the psychometric, experimental, and ecological approaches to studying spatial performance and spatial competence. They made a strong case for using the ecological approach in conjunction with psychometric and experimental methods. Kirasic and Allen stated that age-related decrements are often seen in studies involving abstract components and unfamiliar contexts. It is not clear whether decrements would be seen in real life situations. Their conceptual framework requires that research with older adults consider 1) individual characteristics (including processing abilities, personality variables, physical attributes, and neurological states), 2) situations (what tasks and in what settings), and 3) adaptive processes (cognitive activities necessary for performance).

Others have questioned whether traditional tests are appropriate for older adults. Baltes and Willis (1982) argue that many older adults don't live in environments in which the cognitive abilities tested by traditional intelligence tests are relevant. They 
stress the intraindividual plasticity in older adults and question whether performance on an intelligence test is important to the lives of the elderly. However, there may be age-related limits on the amount of plasticity in older adults. Baltes (1987) recognizes that plasticity within individuals and age groups varies and encourages the research strategy of "testing-the-limits." Applying this strategy through variation in the modes of assessments, one can measure three aspects of plasticity: 1) the baseline performance or what a person can do on a task without intervention, 2) baseline reserve capacity or the person's optimal performance, and 3) developmental reserve capacity or when intervention or development strengthens a person's baseline reserve capacity. Baltes suggests that the testing-the-limits strategy could be used to obtain information about the range and limits of plasticity in adulthood, as age-related differences could be masked or modified in the "normal" range of functioning (Baltes, 1987).

Others support the idea that the environment is a major factor in plasticity of cognitive performance. A study by Labouvie-Vief and Gonda (1976) demonstrated that elderly women could raise and maintain their cognitive performance when trained in covert self 
monitoring strategies. The authors support the argument that there is plasticity in old age rather than viewing intellectual aging decrements as irreversible and suggest that environmental contingencies play a role in modifying performance levels.

Denney $(1982,1985)$ has questioned the ecological validity of studies. She found that elderly adults have the ability to use more efficient constraint-seeking strategy on a Twenty Question Task, but they do not use it spontaneously (Denney, 1985). In a review of problem solving studies, she concluded that age differences are probably a result of both age change effects and cohort difference effects (Denney, 1985). Denney believes poor performance exhibited by the elderly is a result of cognitive rather than noncognitive variables. She proposed a model of life span development that integrates these findings (Denney, 1982). Her framework makes a distinction between unexercised abilities which are a function of biological potential and the normal environment, and optimally exercised abilities, which are frequently utilized and therefore performed at the highest level possible. The performance level for any one skill depends on the amount of exercise and/or training one has experienced. Abilities that are not frequently exercised will 
follow the curve for unexercised ability. Thus, the argument can be made that older adults do not do as well in lab situations because traditional psychometric tests measure unexercised cognitive abilities that college students are routinely using in their educational pursuits.

A study by Denney and Palmer (1981) presented two types of problem solving tasks, one typically used in experimental research and one composed of practical situations. The study demonstrated that in traditional problem solving tasks, performance decreased linearly with age. However, performance on the practical tasks increased to a peak in the 40-50 year olds and declined later. The outcome of the study demonstrates that performance on practical problems may exhibit a different relationship with age. Further, Denney and Pearce (1989) have found that elderly adults perform relatively better on practical problems than traditional problemsolving problems compared to young adults because of their additional life experiences. However, a recent study (Denney, Tozier, \& Schlotthauer, 1992) examined whether the type of instructions given to subjects affected their performance; specifically, did young adults not perform optimally in earlier 
studies because they were not encouraged to do so. This study compared the performance of young, middle-aged, and old adults on practical problems under two conditions of instructions (i.e., standard instructions and instructions that facilitated optimal performance). Denney et al. found that when presented with standard instructions, young adults performed less well than middle-age or older adults, but with more explicit instructions young adults performed as well as middle-aged adults and better than older adults. Thus, this suggests that, although life experiences (or practice) may compensate for age-related decline in older adults, it may not be great enough to bring their level of performance up to young adults.

Results of a recent study (Dixon, Kurzman, \& Friesen, 1993) also suggest that familiarity and practice play a role in the speed of handwriting. In two experiments, young and old adults were compared on familiar and unfamiliar handwriting tasks. In the second experiment, subjects were given ten trials to examine practice effects. Although young adults performed faster than older adults on all tasks, the age differences were magnified for unfamiliar and attenuated for familiar tasks. Further, older adults 
improved faster than young on the unfamiliar tasks with the practice trials. Thus, although handwriting skills show the same slowing with aging as other psychomotor and cognitive skills, this study suggests that practice and familiarity played a role in the magnitude of observed age differences (Dixon, Kurzman, \& Friesen, 1993).

Others have questioned the ecological validity of traditional experimental tasks. Sharps and Gollin (1987) compared the spatial memory of young and old adults on two tasks; on one, common objects were displayed on a map and, on another, objects were displayed in a "real life" room. The older adults had lower spatial memory in the map condition than the young adults, but performed just as well as the young in the room condition. Sharps and Gollin hypothesized that age-related decline for spatial memory is not a characteristic of aging, per se, but derives from an interaction of age and task conditions. They indicated that the visual distinctiveness between the two conditions made the difference. They further suggested that the elderly may be better in spatial memory in the real world because the visual distinctiveness of their everyday environment in contrast to many lab or clinical tests. They 
further emphasize the need to assess the older adults in their typical environment.

In a study designed to compare young and old adults on the effects of contextual integration with the recall of pictures, Park, Smith, Morrell, Puglisi, and Dudley (1990) found that age differences were largest when the target and context of picture stimuli were poorly integrated, but well integrated target-context relationships facilitated the recall of older adults more than younger adults. Additionally, the older adults benefitted with both conceptual and perceptual integration, whereas young adults benefitted only if there was a conceptual relationship between the target and contextual cue. These results suggest that older adults may be more sensitive to context than younger adults.

Akiyama, Akiyama, and Goodrich (1985) compared fifth grade, ninth grade, college students, and older adults on spatial ability measured using three pencil-and-paper tasks. Two tasks involved drawing water lines on both a tilted water bottle on a horizontal stand and a tilted water bottle on a tilted stand. The third task involved giving directions from one place to another on a hypothetical map. The older adults' performance was equal to that 
of the college students when drawing the line on the bottle on the horizontal stand, but poorer than that of young adults when drawing a line when the bottle was on a tilted stand. However, on the third task, giving directions, older adults performed better in terms of accuracy (use of compass points) and completeness (all departing, arriving, and turning directions are given) than college students. One way to explain the tilted water results is that the task requires integration of two cues. Another explanation offered by Akiyama et al. is in terms of ecological validity of the tasks. Observation of water lines in real life is almost always in a horizontal plane. Thus, when the task was more ecologically valid, the detrimental effect of age was not observed. This explanation is supported by the results of the direction-giving task since the older adult likely has had the of experience giving directions.

In a recent study, Kirasic (1991) compared the performance of young and old adult women on four tasks in familiar and novel environments (e.g., supermarkets). Results provided little support for a general age-related deficit in spatial cognition, in that the elderly adults performed as accurately as the young in three of the four tasks in the familiar environment. Further, the young 
demonstrated no significant difference in their performance in the two environments (familiar and unfamiliar). However, the older adults performed more accurately in the familiar environment than the novel for two of the complex tasks. This suggests that there is some age-related decrease in the efficiency of spatial learning; young adults can easily acquire spatial knowledge compared to older adults. It also suggests that there is not a general beneficial effect of environmental familiarity for both age groups, but older adults may show less age-related decline when functioning within a familiar environment.

In another study examining spatial problem-solving with different environments, Kirasic (1990) found similar results. When presented with a novel spatial array, older adults were less accurate than young and middle-aged adults with perspective-taking and mental rotation (spatial problem-solving) instructions. However, when the same problem was presented using the location of the subjects' hometown, there was no difference in the performance between the three age groups. Thus, these findings suggest that familiarity of the task setting, or context, has an important influence on task performance. 
Botwinick (1984) notes that the elderly were

disproportionately benefitted when material is relevant and familiar. However, this may not always be true. In fact, Salthouse (1991) recently argued that ecologically valid activities or studies are difficult to interpret because a) there is little information currently available concerning the frequencies of natural or familiar activities, nor is there consensus at which level of analysis the evaluation of frequencies should be studied, and b) there is potential confounding of chronological age and experience, as older adults may have the benefit of more relevant experience than younger adults. Thus, a finding of no age differences in measures of performance from presumably familiar tasks has little meaning since there is difficulty distinguishing between the effects associated with increased age and those associated with greater experience.

However, if the outcome of such a study yields results where young adults perform at higher levels than older adults, it would suggest that age-related deficits are present even when there are positive contributions of more extensive experience (Salthouse, 1991). This, in fact, has been shown to be true in many studies that have used tasks considered to be ecologically valid and thus, overall, has 
supported the external validity of traditional laboratory studies

(Salthouse, 1991). For example, Foos (1989) compared the recognition memory performance of old and young adults in a nonlaboratory setting using the common, everyday items of a pushbutton telephone dial and the top side of a United States penny. He found that older adults had more incorrect responses, but were more confident in their responses than the young adults. Thus, his study supports the external validity of laboratory results in recognition memory.

In line with the concept of unexercised and exercised abilities is the study of expertise. Salthouse (1985b) and others (Rybash, Hoyer, \& Roodin, 1986) suggest that extensive experience or expertise can compensate or overshadow the negative effects of aging in efficiency of functioning. Salthouse (1985b) further suggests that because practice contributes to changes in efficiency, it may be impossible to predict real world functioning on the basis of lab performance; that is, performance on lab tasks may not be generalizable to well practiced activities. It may be that differing degrees of experience (practice) contribute to discrepancies in 1) age trends in different types of behavior and 2) age trends in 
laboratory and real world experiments (Salthouse, 1985b). Perhaps the best example of this type of discrepancy is in Salthouse's classic study of typists. Salthouse found that older typists had increased reaction times, but they still maintained rates of typing that were independent of age. The implication is that the older typists develop compensatory mechanisms that allow them to maintain a high level of typing proficiency despite declines in speed of perceptual and motor processes (Salthouse, 1984, 1985b).

A recent study (Bosman, 1993) replicated the findings of Salthouse (1984) with typists. Bosman found that older, highskilled typists had age-related slowing on an unpracticed task (a novel choice reaction time task), but performed as well as young, skilled typists on the skill-related tasks. Further, older, low-skill typists demonstrated age-related slowing on execution processes while the older, high-skill typists did not. These results strongly suggest that, under certain conditions, age-related slowing of motor performance is not apparent with older adults, given sufficient practice.

Another recent study (Geary, Frensch, \& Wiley, 1993) examining strategy choice and speed-of-processing differences in 
young and old adults also illustrates the possible positive effect of practice for older adults. Subjects completed simple and complex paper-and-pencil and computer-presented subtraction problems. Analysis suggested that older adults were slower at number encoding and number production, but faster at executing the borrow procedure. Further, there were no group differences in the speed of subtraction fact retrieval and older subjects had faster overall solutions times. Thus, these results could be seen as support against the argument that age differences in processing speed increase with greater task complexity. However, Geary et al. argue that these results are misleading. They explain that the older cohort have had a superior basic mathematics education in addition to benefitting from practice using math throughout their adult life. They, therefore, support the use of mathematics in aging research as a more ecologically valid task than using other cognitive strategies to examine processing time.

Expert knowledge has often been described as domain specific, automatic, and intuitive (Rybash et al., 1986). The expert or skilled performer is able to produce precise behavior with the least amount of effort, is quicker to detect and correct errors, and can adapt to a 
variety of situations while still performing optimally. Because experts can perform with fewer attentional demands, they are more resistant to distraction from outside sources and better able to handle two activities simultaneously (Salthouse, 1985b). Salthouse (1985b) has developed a taxonomy of explanatory mechanisms to describe the nature of skill and expertise. These elements are closely related to the descriptors of performance in the AMPS and explain how the expert differs from the novice.

On the other hand, several recent studies have suggested that experience neither mediates nor moderates age-related differences, at least for certain measures of spatial ability (Salthouse, 1991; Salthouse \& Mitchell, 1990; Salthouse, Babock, Skovronek, Mitchell, \& Palmon, 1990). Salthouse et al. (1990) investigated spatial visualization ability in unselected adults and adults with extensive spatial visualization experience (e.g., architects). They found lower performance scores on tests of spatial visualization were associated with increased age for both regardless of experience, though age differences were less pronounced with individuals whose occupation provided them with extensive experience in using spatial visualization. Salthouse and Mitchell (1990) provided further 
evidence that age-related effects on measures of basic abilities in spatial visualization are independent of the amount of relevant experience. Statistical control of experience on a questionnaire designed to assess experience with spatial visualization activities resulted in only small attenuations of the relationship between age and spatial visualization performance. Lastly, Salthouse (1991) investigated the effects of age and experience on the interpretation of orthographic drawings of three-dimensional objects. Findings indicated that age-related differences were not significantly attenuated by increasing experience and there were no significant age and experience interactions.

These results have been supported in another study (Lindenberger, Kliegl, \& Bates, 1992) based on a testing-the-limits paradigm testing imagery-based memory performance with expert graphic designers. This study investigated whether a group of older experts with experience in the production of visual images could perform as well as younger adults with and without similar taskrelevant experience. Although the older experts performed better than their older control subjects, none of them reached the level of performance of the younger control subjects (i.e., those younger 
subjects without task-relevant experience), thus suggesting robust age-related differences in some cognitive processes.

All of these studies dispute the idea that age-related declines in some measures of cognitive functioning are attributable to disuse or lack of experience. However, Salthouse (1991) does express caution regarding the generalizability of these studies to more complex measures of cognitive functioning. Since all of these studies were concerned with relatively basic cognitive functioning and have minimized the contribution of knowledge factors on cognitive functioning, he emphasizes that further research must be done to examine the relationship between age and experience on the more complex aspects of cognition, such as general cognitive functioning or level of competence in one's occupational or daily living activities.

This discrepancy in studies investigating whether expertise can compensate for age-related differences in performance might be explained by two recent studies. First, Morrow, Leirer, and Altieri (1992) investigated whether aviation expertise would eliminate age-related differences in narrative processing of aviation and general narratives. They found that although young and old pilots 
were more accurate in performance, expertise did not eliminate age differences. Since the investigators questioned whether the narratives used in this first study were compatible enough with aviation knowledge and organization, they examined this same question using more domain-relevant tasks in a another study with younger and older pilots and nonpilots. In this study (Morrow, Leirer, Altieri, \& Fitzsimmons, 1994), the tasks were similar to air traffic control communications and thus, were very familiar to pilots. Results showed that age differences were eliminated in the tasks that were highly relevant to pilots (i.e., older pilots performed as well as younger pilots). However, compensation did not occur in tasks that involved relevant materials, but the procedures were not highly related to piloting tasks. These findings suggest that expertise compensates for age-related decline only if the task is highly domain relevant. Therefore, studies investigating whether expertise compensates for age-related decline must examine the tasks closely for relevancy to the supposed experts.

Another variable that does seem to affect an older adult's performance is motivation. Hulicka (1967) reported a high drop out rate with elderly subjects when presenting unfamiliar and nonsense 
syllables. He concluded that older adults need and want tasks that are meaningful and relevant. Adams and Rebok (1982-3) suggested that problem solving ability may not be related to age, but to deficiencies in metacognitive strategies. Two groups of older adults were compared doing an inquiry problem which involved eliminating numbers or letters from an array of stimulus items by asking as few questions as possible. One group had no instruction and the other had instruction on how to best plan and prepare questions. The group given planning instruction performed better than the group with no instruction, but there was no significant difference on the transfer task. The study results suggest that metacognitive strategy deficiencies are at least in part responsible for deficits in problem solving in later life and megacognitive training may lead to improved task performance. The participants did not lack the capability of strategic planning and deliberate search, but failed to initiate operations without inducement. Adams and Rebok suggested that motivational factors may be one of the reasons why older adults do not initiate megacognitive operations spontaneously. To older adults, tasks that are meaningless or self regulatory activities like note-taking may be seen as admissions of 
failure rather than as effective strategies for solving problems.

Adams and Rebok contend that when examining megacognitive activity, it is important to take the sociohistorical context of the older adult into account.

On the other hand, Grant, Storandt, and Botwinick (1978) found no differential age effects of motivation in digit symbol performance. In another study, Robinson and Ross (1978) compared the performance of elderly subjects on Piagetian tasks with and without provision of incentives. Results were not significant, suggesting that techniques for increasing motivation did not make any difference in performance and were of limited effectiveness unless linked with training of new strategies. Further, Kausler (1990) recently reviewed studies concerning motivation, aging and cognitive performance. His summary indicated that most studies showed that increasing motivation incentives does increase performance scores, but equally so for both young and old adults. That is, motivational factors do not appear to account for agerelated differences in cognitive performance. However, Kausler does suggest that there may be a potential variable in extrinsic motivation that has not been given adequate attention in aging 
research - that of control. Typical laboratory studies offer no opportunity for control and Kausler admits that such control may be differentiately motivating for older adults.

\section{Choice as a Control Variable}

It is fairly well established that a sense of control is important to an individual. Schulz (1980) maintains that a sense of control is important for health and well being, particularly among the elderly. In fact, Schulz, Heckhausen, and Locher (1991) argue that older adults increasingly use cognitively based secondary control strategies (accommodating oneself to existing realities) to minimize the losses in the biologically based primary control strategies (shaping existing physical and social realities to fit ones' perceptions, goals, or wishes). That is, individuals prefer primary over secondary control, but resort to secondary control processes because their use enhances or maintains the potential for primary control. This is consistent with the attributional analysis of learned helplessness (Abramson, Seligman,\& Teasdale, 1978). According to this analysis, if an individual feels powerless to affect an outcome in the environment in a variety of situations, the individual may demonstrate symptoms of helplessness. 
Weisz (1983) describes two factors that must be selfassessed to accurately judge the capacity for control - contingency and competence. Contingency is the degree to which the outcome is dependent upon variation in the behavior of the person. Competence is the degree to which one is capable of producing those behavioral variations (Weisz, 1983). Thus, how an individual judges his or her contingency and competence in a specific task will determine the degree of control he or she feels over the situation. This is important since the judgement of control influences where one invests personal energies, how long one persists at a task, and how effectively one attends to the task (Lachman, Steinberg, \& Trotter, 1987; Weisz, 1983). Further, Lachman and Jelalian (1984) suggest that expectations and beliefs about functioning not only affect task choice, motivation, effort, and anxiety, but actual performance as well.

According to the self efficacy theory (Bandura, 1981), those who are insecure about their efficacy (i.e., competence) are likely to curtail their range of activities and undermine their efforts in those they do undertake. Moreover, a sense of efficacy that is decreased may lead to losses in motivation and skills (Bandura, 1981). That is, 
as one's self esteem decreases, the belief in one's ability to control the environment decreases which may affect performance (Langer, 1979; Rodin \& Langer, 1980). It would appear that older adults are particularly vulnerable to the effects of this phenomenon.

Specifically, Weisz (1983) suggests that old age is associated with loss of contingency and the elderly have low perceptions of contingency between their behavior and outcomes of daily life. Lachman (1986) also indicates that the elderly believe they have less control over intellectual functioning than the young. In a five year longitudinal study, changes in intellectual control beliefs in a group of elderly were evident even though there were no changes in generalized control or intellectual performance (Lachman \& Leff, 1989). On the other hand, Rhee and Gatz (1993) found that college students attributed higher levels of externality to older adults than the older adults actually ascribed to themselves and the older adults in this study manifested higher levels of internality than the college students. However, Rodin and Langer (1980) have demonstrated that negative labels and stigmatization of the elderly lead to lower self esteem, decreased feelings of control, and deficits in performance. They found that when the environment was structured to be more 
demanding, it was more motivating to the elderly and performance was increased. Other studies have also found that the perception of control is important for the elderly (Lachman, Baltes, Nesselroade, \& Willis, 1982; Langer \& Rodin, 1976; Perlmuter et al., 1986; Ryden, 1984).

Thus, the implication is that providing control enhancing conditions would significantly improve performance. Although true in many cases, manipulation of control may not enhance performance under all conditions. First, the environmental context in which the interventions are carried out may have an effect. Schulz and Hanusa (1979) replicated control- and competence-enhancing interventions in two experiments, one with institutionalized elderly and one with college students. Results demonstrated that the combined effects of the enhancement interventions for the college students were greater than the impact of either intervention alone, as one might expect. However, for the elderly, the subjects under the combined enhancement condition exhibited declines relative to the other treatment groups. Although there were many differences in the two experiments, Schulz and Hanusa argue that the environmental context was the most notable difference. They explain that the 
opportunities to exercise competencies in the college environment are infinitely greater than the long-term-care facility for the elderly and thus suggest that interventions aimed at improving self concept or control should be accompanied by appropriate environmental alterations.

Secondly, control enhancement may be subject to individual differences. Recently, Reich and Zautra (1990) demonstrated control enhancement was most effective with those individuals with high internal control beliefs. Subjects with low control beliefs did not respond strongly to control manipulations. Along the same lines, Lachman et al. (1987) found that those individuals with stronger internal control beliefs performed better in a memory test and demonstrated fewer decrements in self assessments across trials than individuals with external control beliefs.

Thus, from this brief discussion, it is obvious that control is an important, but complex construct to be addressed. In fact, Lachman et al. (1982) found that locus of control is one personality dimension that is of central importance to the study of intellectual aging. In this particular study, control will be contrasted under conditions of choice and nonchoice. The implication would be that 
when subjects are given the opportunity to choose a task in a facilitating environment (their own home), they would have a greater sense of control, thus be more motivated, and therefore performance would be greater. There is literature to indicate this would be true under certain conditions.

Perlmuter, Monty, and their colleagues have done a series of studies on the effects of choice and control on the perception of control. Based mostly on a paired-associate learning paradigm of choice versus forced response, they proposed a motivational theory to explain differences in performance when subjects are given an opportunity to make choices during tasks. The theory has evolved through a series of studies with young adults. In addition, others have contributed to the knowledge of how choice affects perceived control. The following is a summary of the results of these studies. In most of the experiments, using paired-associate learning, choice was the major variable manipulated. In the choice condition, subjects were presented with a series of stimulus words accompanied by some number of potential response words. The subject then selected the response word that was to be learned with each stimulus word. In the comparison or forced condition, the 
subjects were exposed to the identical sets of materials, but were informed which response word as to be learned. Subsequently, when given a choice, subjects perform better than those subjects not given a choice, and this facilitated performance persists even after a 24 hour period (Monty \& Perlmuter, 1975).

However, it is not the act of choosing per se that activates the motivational mechanism, but it is the perception of control that plays the critical role (Bailey, Perlmuter, Karsh, \& Monty, 1978; Perlmuter \& Monty, 1977; Savage, Perlmuter, \& Monty, 1979). That is, only when the act of choosing results in perceived control will motivation be increased. Further, by comparing the number of choices and meaningfulness of response alternatives in nine experimental groups, Savage et al. (1979) demonstrated that perceived control is established by providing subjects with the potential opportunity to choose rather than actually following the act of choosing. This was supported in another study (Chan, Karbowski, Monty, \& Perlmuter, 1986) in which the opportunity for choice was sufficient to generate the perception of control - the choice did not actually have to be exercised. In this study, they found that when offered a choice, subjects had longer response 
latencies. Chan et al. suggested that these longer response latencies are reflective of a more thoughtful decision process. Thus, if subjects are utilizing information to evaluate the effectiveness of their behavior in respect to control, they will likely increase perception of control and enhance motivation.

However, the act of choosing is not sufficient to increase motivation, as demonstrated by the Bailey et al. (1978) study. In that study, subjects who did the choosing for themselves performed significantly better than those choosing for others or offered no choice. The implication is that those who chose for others did not perceive control to the same degree as those who chose for themselves. Further, it has been shown that subjects who are given a choice and who then must do the forced learning task do worse than subjects who only do all forced tasks (Perlmuter, Monty, \& Cross, 1974).

When the choice is enacted appears to affect perception of control. Apparently, perception of control must be established early for the benefits to appear (Monty, Rosenberger, \& Perlmuter, 1973; Monty, Geller, Savage, \& Perlmuter, 1979). In fact, Monty et al. (1973) found that those subjects who chose the first three 
responses and were assigned the remaining nine stimulus-response pairs in a twelve item paired-associate paradigm performed almost as well as those subjects who chose all twelve responses. Moreover, subjects given the opportunity to choose the last three responses performed as poorly as those who were given no choice. Also, in another study, Savage et al. (1979) found that reducing future opportunities of choice only affected the subjects' behavior if a perception of control was established previously. Those subjects who had not developed a perception of control were unaffected by the reduction. Further, when subjects do perceive control and demonstrate increased performance, the beneficial effects have been shown to generalize to another task in which there was no choice (Perlmuter, Scharff, Karsh, \& Monty, 1980) and even to an unrelated task that offers no choice (e.g., a dice game) (Chan et al., 1986), thus establishing more evidence for the motivational hypothesis.

However, choice alone may not lead to a perception of control. It is only when the subject feels there is a "real" choice that the perception of control develops (Harvey \& Johnston, 1973; Perlmuter \& Monty, 1977; Savage et al., 1979). That is, the beneficial effect of 
choice will only occur if the choices are between similar alternatives. Thus, perceived choice is greater with small differences in attractiveness in outcomes of alternatives and under conditions of low certainty about outcomes than under conditions of high certainty (Harvey \& Johnston, 1973). If subjects perceive the alternatives as dissimilar, they will perform as if there were no choice at all (Monty et al., 1979; Savage et al., 1979). Interestingly, the perception of control is important even when there is no overt choice possible. Subjects who did not have the opportunity to choose, but recognized that they would have been better off had they had the opportunity because the alternative was more desirable, expressed frustration and had decreased performance relative to subjects who were forced in the presence of similar alternatives (Savage et al., 1979).

Lastly, under certain conditions, subjects may react negatively to increased perceived control or have increased negative mood. Burger, Brown, and Allen (1983) found that when subjects are not competent, choice will lead to depressed feelings. They suggest that, although people generally want to have control, if they are concerned about how they are perceived by others, subjects may 
react negatively to perceived control. Self preservation comes into effect because people do not want to be seen as incompetent, particularly if they chose the task.

The beneficial effects of choice have been found in the elderly although there are only a limited number of studies. Specifically, Fleming and Lopez (1981) had elderly subjects (ages 69-87) perform a modified paired-associate learning task under two control enhancement conditions (choice of items and self pacing). Results demonstrated that the subjects did significantly better than yoked subjects when given either choice or self paced tasks, thus lending support to the motivational theory with elderly individuals.

Similar results were obtained in a study by Perlmuter and Smith (cited in Perlmuter et al., 1986) with older adults (ages 6075) who reported difficulties with memory. These results indicated that subjects who were able to choose their own response words in a paired-associate experiment performed significantly better than those assigned in the forced condition. Additionally, these subjects had fewer intrusion errors.

Choice may also increase the perception of control for the performance of daily living activities. It is generally recognized 
that with behavior that has become automatic or mindless (Langer, 1979), individuals may fail to perceive the existence of choices. Thus, Perlmuter and Langer (1982) conducted a pilot study with elderly men examining the effect of monitoring routine behaviors. Although it was only a small sample, they found that individuals who became aware through monitoring that there were choices to be made, even in routine activities, reported the perception of control as increased.

However, not all studies with elderly individuals have found perceived choice to increase performance. Taub, Baker, and Kline (1982) conducted three experiments to evaluate the effects of perceived choice upon the comprehension and memory of prose reading passages with young and old adults. In these studies, perceived control did not show any effect on the performance of the elderly even though a questionnaire included in two of the studies indicated that subjects did select their own reading materials. However, the authors reported a high interest level of the subjects in all conditions and suggest that the prose task utilized in the studies may have provided enough motivation to obscure the possible effects of perceived control. 
Similarly, a study on the effects of control on memory for spoken language was investigated by having young and old adults take actual control of input conditions of narratives (i.e., they could stop the recording any time for any length of time) and under a condition of no control (Stine, Lachman, \& Wingfield, 1993). Results indicated that there was little or no direct relationship between perceived control and the tendency to engage in control behaviors. Further, older adults were less likely to engage in actual control behaviors when given the opportunity and were more likely to endorse the idea that their cognitive performance was due to chance rather than their own efforts. Therefore, Stine et al. suggested that actual and perceived control are relatively independent influences in the determination of age differences in cognitive performance, though interrelated, as perceived control was a stronger predictor of prose memory when no actual control was available.

In summary, it would appear that, when presented with an opportunity to make a choice between two similar alternatives, individuals demonstrate improved performance due to their increased perception of control. This effect appears to benefit the performance in both young and old adults, even those older adults 
with cognitive decline. Therefore, it can be argued that perceived control in the form of choice will significantly affect the performance of tasks, although it does not appear to eliminate agerelated cognitive deficits. However, failure to consider the influence of motivation through perceived control can lead to an exaggeration of the magnitude of age-related decline in cognitive performance (Perlmuter \& Monty, 1986).

Therefore, perception of control (i.e., choice of task) was an essential variable in this study. Further, there is a particular need to look at this phenomenon with older adults, because there is a lack of research on perceived control in the elderly as compared to young adults. Moreover, most of the research has been done with a pairedassociate learning task and not with functional tasks of daily living.

\section{Purpose of Study}

The purpose of this study was to compare the functional performance of young and old adults on familiar and unfamiliar tasks under two conditions of perceived control. Specifically, the relation between age and motor and process (cognitive) skills was examined. This study was based on the assumption that older individuals are more likely to have some process and motor skill 
deficits in traditional laboratory tests, but may be able to compensate for inefficiencies or deficits and perform effectively on tasks that are familiar, performed in their normal, selected environment, are meaningful and practiced, and when they are offered a choice of tasks. Results of an earlier study of the same nature (Dickerson, 1991) suggested that older adults demonstrated poorer performance than young adults on both unfamiliar and familiar activities. However, the element of choice was not presented in this previous study and the unfamiliar task was not totally unfamiliar to all subjects. Therefore, this present study was designed to demonstrate more clearly the relationship of age to functional performance under conditions of perceived control. Specifically, the research hypotheses for this study were:

1. Young adults will demonstrate higher performance on tasks than older adults (main age effect).

2. Young and old adults will demonstrate higher performance on familiar tasks than on unfamiliar tasks (main task effect).

3. Young and old adults will demonstrate higher performance on chosen tasks than on assigned tasks (main choice effect).

4. Old adults will demonstrate lower performance than young 
adults on unfamiliar tasks, but not on familiar tasks (age $x$ task interaction).

5. Subjects will perform differently for the two types of tasks under the two conditions of control (choice $x$ task interaction).

6. Old adults optimal performance will be under the conditions of performing a chosen, familiar task and may equal the young adults' performance, whereas the least optimal will be in performing an assigned, unfamiliar task where the discrepancy between young and old adults' performance should be greater (age $\mathrm{x}$ choice $\mathrm{x}$ task interaction). 


\section{Chapter 3: Methodology}

\section{Subjects}

Subjects were 59 English-speaking adults, consisting of 28 community living healthy elderly volunteers between the ages of 59 and $81(M=69.1, S D=5.17)$ and 31 community living healthy young adults between 21 and 41 years of age $(M=29.9, S D=5.07)$. All subjects were required to have at least a high school education and to report their health as an 8 or above on a scale of 1 to 10 , with 1 being poor health and 10 being excellent health.

Sixty-four subjects actually participated in the study which included 22 males and 42 females. However, five subjects were eliminated from the analysis because they either did not complete the study or did not meet the inclusion criteria. Subjects were recruited by advertisements, telephone requests, and subject referrals in the Denver area. During the data collection process, a grant was awarded to the researcher to fund the rest of the study. At that time, recruited subjects were paid $\$ 20.00$ for their participation. Most of the older subjects and approximately onethird of the young subjects thus recieved payment for their participation. 
The young adults consisted of 11 males and 20 females and the old adults included 9 males and 19 females. The mean health score for the young adults was $9.00(S D=1.05)$ and for the older adults the mean was $9.03(S D=.80)$. These means were not significantly different $t(50)=-.13, p<.90$. However, the mean educational level for the young adults was 14.71 years $(S D=1.77)$, compared to 16.14 years $(S D=2.97)$ for the older adults, which was a significant difference, $t(57)=2.28, p=.03$.

Prior to the start of the main study, a survey was completed to assist in determination of the study's tasks. For this preliminary phase of the study, 150 young adults from the student body of Florida International University and 120 older adults from a mailing list established by the Elder's Institute of Florida International University were asked to complete the survey. In total, 122 surveys were completed by the young adults and 44 surveys were returned by the older adults.

\section{Instrumentation}

The instrument used in this study was the Assessment of Motor and Process Skills (AMPS) (Fisher, 1990;1994). It is a criterion-referenced observational assessment that evaluates an 
individual's ability to organize and execute a daily living task as shown by effective, efficient, and timely completion of a specified task (Fisher, 1990; 1994). A unique feature of the AMPS is that the discrete motor and process skills assessed during the completion of a specified task are evaluated directly in the context of the subject's actual performance of the task. Moreover, the ability of an individual to perform functional tasks of daily living is evaluated independent of the person's individual style of performance.

AMPS consists of two scales, motor and process, which are hypothesized to represent two universal taxonomies of component skills required for all task performance (Fisher, 1990; 1994). Motor skills are observable actions that an individual uses to move the body or the task objects during the performance of a task. These motor skill actions are related to underlying postural, mobility, coordination, and strength and effort elements of action performance. Process skills are related to underlying attentional, knowledge, organizational, and adaptive elements of performance and are the observable actions the individual uses to logically organize and adapt his or her behavior in order to complete a specified task (Fisher, 1990; 1994). Appendix A contains the motor 
and process skill items definitions. Appendix B is a copy of the score sheet for the assessment along with a sample of scoring for one of the skill items.

Analysis of the raw data generated from the AMPS is based on the Rasch measurement model (Wright \& Masters, 1982; Wright \& Stone, 1979). The Rasch measurement model is a one-parameter latent trait model that can be used to develop criterion-referenced hierarchical scales (Hambleton, 1989). Specifically with the AMPS, the many-faceted Rasch analysis (Linacre, 1989) is being used through the FACETS computer program at Colorado State University. It is an expansion of the single Rasch measurement model which provides a theory for a) item analysis and selection and b) a measurement scale for reporting scores (Isaac \& Michael, 1984). It is the stochastic or probabilistic equivalent of Guttman scaling such that Rasch probabilities are Guttman ordered (Wright \& Masters, 1982; Wright \& Stone, 1979).

The many-faceted Rasch model specifies the following expectations: a) a person of higher ability will obtain higher scores than will a person of lower ability, b) a person has a higher probability of obtaining a higher score on an easy item than on a hard 
item, c) easier skill items are easier for all persons than are hard items, and d) persons obtain higher total scores on less challenging tasks than on more challenging tasks (Lunz \& Stahl, 1990;

Silverstein, Kilgore, \& Fisher, 1989; Wright \& Masters, 1982). The data (raw skill item scores) are modeled according to these specifications until the expected (estimated) responses predicted by the model are as close as possible to the observed responses (Lunz \& Stahl, 1990). When the data conform to these expectations, they will fit the measurement model.

The many-faceted Rasch model provides a framework from which difficulty of the skill items, the challenge of the tasks, and the severity of the rater are examined and accounted for by constructing a single common variable on which each facet is measured (Fisher, 1994; Linacre, 1989). This is called the calibration process. Skill items are calibrated according to their difficulty and represent positions along a linear scale. Tasks are calibrated along the same linear continua based on their relative challenge and linear adjustments are made for item difficulty depending on the relative challenge of the task performed. Similarly, raters are calibrated according to their rating severity, 
enabling scores to be adjusted for the rater's personal biases and perceptions (Lunz \& Stahl, 1990). In other words, when an individual is evaluated using the AMPS, his or her motor and process performance skills are judged relative to the difficulty of the items, challenge of the tasks, and severity of the rater. Moreover, since each facet is calibrated on the same linear scales, it is possible to compare and predict performance across tasks of greater or lesser difficulty than those actually performed (Fisher, 1990; 1994).

These calibrations and measures are expressed in equalinterval units of measurement based on the logarithm of the odds (log-odds probability units or logits) of obtaining a skill item score when a person of a given ability is observed performing a given task (Fisher, in press; Lunz \& Stahl, 1990; Wright \& Masters, 1982). These logit scores can then be used as ratio level numbers in traditional statistical analyses.

The FACETS Rasch computer program also generates fit statistics which are examined to verify that the scores fit the measurement model's expectations (i.e., the four expectations previously listed). Specifically, the mean-square residuals (i.e., differences between observed and expected scores) provide a 
measure of the degree to which the skill items and tasks fit the expectations of the Rasch model. A "misfit" will be identified when there is an unexpected response within the measurement model. For example, if a specific rater scores a particular item more strictly than he or she scored other items, that rater-item interaction will misfit. Similarly, if a person of lower ability gets a higher score on an item that measures higher ability, there will be a subject-item misfit. When these deviations are identified, person response validity can be verified by evaluating the effect of the misfitting rating on the estimation of the subject's ability (Fisher, 1990; 1994). These fit statistics are a standardization of the mean square $(\mathrm{MnSq})$ fit statistic such that standardized score residuals are expressed as standard deviations from the expected value of zero (Wright \& Masters, 1982). In other words, any discrepancies in the fit of the items, raters, or tasks are identified by examining the mean square standardized residuals (i.e., $\mathrm{MnSq}$ ) and the standardized mean square goodness-of-fit statistics (i.e., $t$ values (Fisher, 1993)). In this study, the criteria for misfit are a $\mathrm{MnSq}<1.4$ or $>.07$ and a $t$ value $\leq 2$ or $\geq-2$. If any item, task or rater, falls outside both these criteria, they need to be considered misfit and need to be 
closely examined.

Finally, the many-faceted Rasch measurement model's advantage is that measurement is sample-free for the items and tasks and test-free for the people. That is, the measuring function of the AMPS scales is not affected by the sample used to calibrate the items and tasks (sample-free), and it is possible to evaluate a person's ability regardless of which items and tasks the person actually performed (test-free) (Fisher, in press; Linacre, 1989; Wright \& Stone, 1979).

Several studies have supported the interrater and intrarater reliability among trained raters and the concurrent and construct validity of the AMPS (Bernspång \& Fisher, 1993; Dickerson \& Fisher, 1993; Doble, Fisher, Fisk, \& MacPherson, 1992; Fisher, 1993; Fisher, 1994; Fisher, in press; Fisher, Lui, Velozo, \& Pan, 1992; Fisher et al., in press). Further, studies indicate that the AMPS is not culturally biased (Dickerson \& Fisher, in press; Fisher, 1994; Fisher, Lui, Velozo, \& Pan, 1992; Magalhães. Fisher, Bernspång, and Linacre, 1993). The test manual is available for review upon request.

\section{Procedure}

Phase 1. Because experiential and motivational factors may 
influence the quality of performance, it was important that the familiar activities were highly practiced and valued. Therefore, a survey was developed based on the tasks utilized in the AMPS and completed by a total of 166 subjects (See Appendix C). The objective of the survey was to select six daily living tasks for the study that would be familiar tasks for the subjects in the study. Results of that survey are shown in Table 1. Five of the tasks (setting a table; french toast; eggs, toast, meat, and beverage; and repotting a plant) from the survey were eliminated as possible tasks because a high percentage of the respondents did not indicate these tasks as the most familiar from the list.

Next, a pilot study was completed with 10 individuals who performed the eight most frequently selected tasks. Based on the results from the pilot study, ironing a shirt or blouse, plant care, and vacuuming the living room were eliminated because they were not challenging enough to be appropriately scored by the AMPS with healthy subjects. Thus, the final six tasks consisted of preparing 1) a green salad, 2) a tuna sandwich, 3) a grilled cheese sandwich, 4) a scrambled egg mixture with toast and beverage, 5) fruit salad, and 6) two eggs with toast and beverage. A written description of each 
of these tasks was developed to be given to subjects as directions for the task during the main study. Appendix $D$ is a copy of the written directions for the six familiar tasks.

On the other hand, the unfamiliar activities needed to be completely alien to the subjects. Nine tasks were created with written descriptions for each of the tasks. Each of the nine tasks consisted of a different medium and were given a descriptive name. After construction of each task, a pilot study was completed with 10 young adults. Each of these subjects completed the nine tasks following written directions. After completion, they rated their familiarity with each task on a 5-point Likert scale with "1" being very unfamiliar and "5" being very familiar. Although none of the tasks were rated as familiar, based on the feedback from the pilot study, several of the tasks were eliminated because they either were too simplistic (i.e., were completed so quickly that an adequate assessment was not possible) or the directions were too ambiguous for the subjects to understand what needed to be done. All tasks were changed for either greater ease in administration or to ensure consistency in the end product. Further, written directions for each of the final six unfamiliar tasks were edited for increased 
simplicity and understanding. Thus, the final six tasks consisted of

1) cheeriopotato (placing a peeled raw potato, covered with sugar on

a glass of water after piercing it with toothpicks and placing cheerios on the toothpicks), 2) canned tent (making two flour and water dough balls and placing them on top of a sheet that is placed over two chairs with the four corners held down by a can of food on top of washcloth), 3) dark secret (cutting strips of newspaper, mixed with popcorn in a container, then covering the mixture with soil, macaroni, and salt and placing it in a specific place), 4) hold that water (screwing 6 to 8 screws in a precut board, winding string around the screws to make a structure strong enough to hold a cup of water, 5) PVC lunch (putting together pieces of PVC pipe into a three legged structure that has boiled string hanging over the pieces and a peeled carrot dangling from the center joint), and 6) hang them high (hanging 6 boiled clothes pins from string of varying lengths from a wire coat hanger which has a ribbon decorating its neck). Appendix $E$ contains a complete list of the unfamiliar tasks and the directions used in the main study.

Phase 2. The 59 subjects were observed and videotaped in their home performing four familiar tasks and four unfamiliar tasks. 
Observations were conducted by the investigator, following established test guidelines, in two separate testing sessions. The two sessions were designated as the choice session and assigned session. Half of the subjects in each age group performed their choice session first and half performed the assigned session first. To ensure that the two sessions would not influence each other, the two sessions were scheduled about a week apart. For the young adults, the average number of days apart was $6.10(S D=3.93)$; the average for the older adults was 7.00 days $(S D=5.54)$. the means were not significantly different, $t(57)=.70, p<.49$.

In the assigned session, two of the familiar and two of the unfamiliar tasks were randomly assigned to each subject. In the choice session, the subjects chose four tasks, two from the four remaining familiar and two from the four unfamiliar tasks to complete during the testing session. Table 2 illustrates the tasks subjects completed for the assigned and choice sessions by age group.

After each testing session, subjects were asked to rate the tasks performed in that session in terms of familiarity on a 5-point Likert scale with "1" being very unfamiliar and "5" as very familiar. 
Under each of the four conditions, the familiarity ratings of the two tasks performed were averaged together and compared between the two age groups. Table 3 illustrates the means of the four conditions for both young and old adults. In Table 4 are the results of an Age (young vs. old) $\times$ Task (familiar vs. unfamiliar) $\times$ Choice (choice vs. forced) mixed analysis of variance (ANOVA) to compare the two age groups under the four conditions. As expected, there was no significant main effect for age or for choice. That is, there was no difference in how young and old adults rated the tasks. Further, regardless of whether the tasks were chosen or assigned, the familiar tasks were rated more familiar whereas the unfamiliar tasks were rated as less familiar, as indicated in a significant main effect for task, $F(1,57)=2157.11, p<.001$. None of the interactions were significant.

Six calibrated raters, trained in the use of the AMPS, viewed and scored the videotapes. The grading scale is based on the matrix exhibited in Appendix F. The primary investigator rated all subjects performing all tasks (total $=504$ ). Almost all subjects were rated by at least one other rater on at least one task. The other five raters were independent of the study (i.e., unaware of the 
hypothesis) and rated 151, 148, 13, 7, and 2 observations for a total of 321 of the 504 tasks (64\%). All raters met the criteria for acceptable interrater and intrarater reliability; the proportion of unexpected ratings was less than $5 \%$ (Fisher, in press). Design

The many-faceted Rasch analysis (Linacre, 1988; 1989) generates two measures for each subject under each condition; a process and a motor measure. Since the process and motor skill items represent separate constructs, the eight measures were analyzed in two separate Age (young vs. old) x Task (familiar vs. unfamiliar) $\mathrm{x}$ Choice (choice vs. assigned) mixed analyses of variance (ANOVAs) with age as the between-group variable and task and choice as within-group variables. 


\section{Chapter 4: Results}

\section{Rasch Measurement Model}

One of the greatest advantages of using Rasch analysis is that you can compare the difficulties of different tasks on the same scale. In this study, six familiar food preparation tasks and six unfamiliar tasks uniquely developed for this study were used. To determine how difficult the tasks were relative to each other, the data (i.e., AMPS raw skill items scores for all subjects) were first analyzed as a combined set. Considering all task performances simultaneously, without regard to study condition, an overall task challenge calibration was determined for each task. These values were then used in subsequent analyses to anchor the challenge level of the tasks. When the data were then analyzed separately, subject ability measures were determined relative to the overall challenge calibration for the tasks. If main study effects were present, separately calibrated condition-specific subject ability measures should shift up or down relative to the task calibrations. More specifically, (a) if there were age effects, the ability measures of older subjects would be lower relative to the commonly calibrated task challenges, and the ability measures of the younger subjects 
will be higher; (b) if there were a choice condition effect, ability measures would be higher for the chosen condition and lower for the assigned condition; and (c) if there were a task effect, ability measures would be higher for the familiar tasks and lower for the unfamiliar tasks.

As explained previously, the FACETS computer program generates fit statistics which are examined to verify that all the raters and tasks fit measurement model expectations. Specifically, the mean-square residuals (i.e., differences between observed and expected scores) provide a measure of the degree to which the raters and tasks fit the expectations of the Rasch model. A "misfit" will be identified when there is an unexpected response within the measurement model. These fit statistics are a standardization of the mean square $(\mathrm{MnSq})$ fit statistic such that standardized score residuals are expressed as standard deviations from the expected value of zero (Wright \& Masters, 1982). In other words, any discrepancies in the fit of the items, raters, or tasks are identified by examining the mean square standardized residuals (i.e., MnSq) and the standardized mean square goodness-of-fit statistics (i.e., $t$ values) (Fisher, 1993). In this study, the criteria for misfit were a 
MnSq $>1.4$ and $<.07$ and a $t$ value $\leq 2$ or $\geq-2$. Table 5 illustrates the goodness-of-fit statistics for the 12 tasks in this study and Table 6 illustrates the goodness-of-fit statistics for the six raters in this study. All raters and tasks for both the motor and process scales were within the acceptable criteria for fit. (Although two tasks (egg,toast, \& beverage and canned tent) and rater 3 had $t$ scores out of the criterion range, their MnSq scores were within the criteria set and therefore, these instances were not considered misfits.)

\section{ANOVAS}

The many-faceted Rasch analysis (Linacre, 1988; 1989) gènerates eight ability measures (i.e., dependent measures) for each subject; a process and a motor ability measure for each of the four conditions. See Table 7 for the means and standard deviations of each of these scores. These two measures (motor and process) were analyzed separately in a Age (young vs. old) $x$ Task (familiar vs. unfamiliar) $x$ Choice (choice vs. assigned) repeated measures analyses of variance (ANOVAs), with age and gender as the betweengroup variables and task and choice as within-group variables. Main effects as well as interaction effects were examined. Preliminary analyses including a between-group gender factor found no 
significant gender effects.

ANOVA results for the motor scale are presented in Table 8. There was a significant main effect for age. Older adults $(M=4.64$, $S D=.40)$ performed significantly lower than younger adults $(M=$ 5.33, $S D=.28$ ) on the motor dependent measure. However, there was not a significant main effect for either task or choice. Additionally, there were no significant interaction effects. Thus, in terms of motor ability, only the hypothesized age effect was supported by the results. That is, regardless of whether the subjects selected or were assigned tasks or whether the task was familiar or unfamiliar, their motor performance did not differ.

The process scale results can be found in Table 9. There was a significant main effect for age. Older adults' $(M=4.81, S D=.37)$ performance was significantly lower than younger adults $(M=5.17$, $S D=.38$ ) on the process dependent measure. There was not a significant main effect for task. However, there was a significant main effect for choice. All interaction effects were nonsignificant. These results indicate the subjects' process skills did not differ significantly when performing the two types of tasks (i.e., familiar versus unfamiliar) and this was true regardless of age. However, 
participants performed significantly better when offered a choice of tasks, although it is not age-related nor task-related, as there were no interaction effects. Thus, for the process measure, only the research hypotheses for main effects of age and choice were supported.

Figures 1 and 2 are graphs of the motor and process scale scores by age. In both cases, the graphs show variability of performance. That is, although most older adults demonstrate lower performance than young, some older adults did as well as or better than some young adults. 


\section{Chapter 5: Discussion}

Results from this study indicate that older adults have agerelated deficits of both a cognitive and motor nature. As expected, younger subjects performed significantly better on tasks that were unfamiliar and meaningless. This replicates the typical laboratory findings of young adults' superior performance over older adults.

Young adults also performed significantly better than the old adults with the tasks of daily living which were rated as familiar and practiced by both age groups. This finding suggests that even with ecologically valid tasks, age-related decline is still demonstrated. Thus, this study supports the findings of an earlier and similar study (Dickerson, 1991) which compared young and old adults' performance on familiar and unfamiliar tasks and found older adults' performance significantly lower on both types of tasks.

It has been hypothesized that young adults are at an unfair advantage in traditional laboratory experiments because the experimental tasks are often unfamiliar, unmotivating, not contextually enhancing, and/or exercise abilities that older adults do not typically utilize compared to college students. Thus, agerelated difference results have been questioned in terms of their 
external validity. In this experiment, young and old adults were compared on activities of daily living that were familiar, meaningful, and exercised by both groups. Further, the tasks were performed in the subjects' home, thus eliminating the impact of a new or foreign environment on their performance. Also, many of the subjects arranged the tasks to be done at the normal time of occurrence during their daily routine. For example, subjects made a tuna salad sandwich and fruit salad which they then served for their lunch after the testing session. The fact that older adults still performed significantly lower than young adults despite ecologically favorable conditions suggests that age-related differences found in aging studies may not be artifacts of the laboratory experiment.

This study does not support the concept that expertise or practice can compensate for age-related decline, at least for those activities used in this study. Assuming older adults have performed ADL tasks for more years than young adults, they should be more "expert" in such tasks. Such expertise should give the older adult an advantage in performance (Bosman, 1993; Denney, 1982; Geary et al., 1993; Salthouse, 1985). However, this was not shown to be the case in this study. It may be that practice over long periods of time for 
these kinds of activities are not differentiately beneficial for the older adult. There are three possible reasons for this.

First, it may be that activities of daily living are not tasks that change with practice or expertise because they are overlearned or too familiar. Individuals learn how to make a sandwich or fry an egg fairly early in life and, as creatures of habit, may not think about how to change their performance patterns to be more efficient or effective unless forced to do so. This would be different from Salthouse's (1985) and Bosman's (1993) studies of older typists who, for job security, might be compelled to develop compensatory mechanisms to maintain high rates of typing despite declines in perceptual and motor processes. Thus, older adults may not develop compensatory mechanisms for tasks of daily living when cognitive and motor deficits occur as they might for other types of tasks.

A second possible reason may be that, although the familiar tasks were rated as familiar by both groups, older subjects may not be "experts" in these kinds of tasks. This possibility may correspond to the results in two aviation studies (Morrow et al., 1992; Morrow et al., 1994). In the first study, old pilots were more accurate in processing aviation and general narratives, but their 
expertise did not eliminate age differences. However, in the second study, when tasks were more highly relevant to pilots, age differences were eliminated. These two aviation studies suggest that compensation for age differences can only occur when the task is highly domain relevant. Thus, it is possible that for the subjects in this study, the familiar tasks used are not highly domain relevant. On the other hand, most people do make sandwiches, eggs, and salads fairly regularly leading to the conclusion that they should be practiced skills.

A third possibility for older adults not demonstrating a practice or expertise effect for daily living tasks is that there may be a ceiling effect for practice on activities of daily living. That is, because these tasks are learned early, young adults may already have benefitted from practice and therefore, could also be considered "experts" in such tasks. However, if true, it would seem results would more likely be equivalent to the above aviation study (Morrow et al., 1994); that is, age differences would be eliminated with young and old adults demonstrating equal expertise rather than the young adults being "more expert" than the old adults.

This study may provide one explanation for the discrepancy 
between cognitive abilities and cognitive competence in older adults (i.e., how older adults perform in traditional laboratory studies and psychometric experiments does not adequately reflect their performance in occupational and daily living activities) (Salthouse, 1990). If the end results of a task, such as making a fresh fruit salad, are compared, the outcome of the tasks were adequately achieved by both young and old adults. However, the process of achieving that outcome may be where the discrepancy lies. That is, all the older adults in this study made appropriate sandwiches, salads, eggs, etc. However, the AMPS is sensitive to ineffective compensation strategies during performance that result in unexpected or inefficient deviations in performance (Dickerson \& Fisher, 1993). For example, if an individual forgets to include an ingredient that they planned to put in the salad until the task is near completion and then adds the ingredient, that person would likely get a lower score and yet achieve an outcome that would be considered appropriate and adequate if only evaluating the end result. In respect to the older adult, early signs of ineffective compensation for memory decline may be emerging even though the outcome is acceptable. Similarly, the motor scale of the AMPS is 
sensitive to early declines in fine motor and subtle postural mechanisms (Fisher, in press). Considering Salthouse's (1990) four possible reasons for the discrepancies between cognitive abilities and cognitive competence (e.g., the differences in the types of cognition assessed, the differential representativeness of subjects or behavioral observations, the different standards of evaluation, and the differing amounts of experience), it would seem, in this case, the different standard of evaluation or the sensitivity of the measurement is the issue. If may be that the quality of an older adults' performance of occupational and daily living tasks may differ when compared to a young adults.

Interestingly, the effect of choice was present with the process ability measure, but not the motor. This suggests that an individual's ability to plan, coordinate and execute motor actions, strength, and endurance are not affected by providing control enhancing conditions. This does not seem surprising considering the many studies that demonstrate age-related differences in motor performance (Amrhein et al., 1991; Light \& Spirduso, 1990;

Meeuwsen et al., 1993; Stelmach et al., 1986; Stelmach et al., 1988; Stelmach et al., 1989; Teasdale et al., 1991; Welford, 1984; 
Woollacott et al., 1986). However, it has been argued that motor performance becomes more variable with increasing age (Spirduso and MacRae,1990) and exercise may eliminate some age-related differences (Baylor \& Spirduso, 1988; Botwinick \& Thompson, 1968). From the motor scatterplots it is clear there is individual variability. However, in this study, exercise was not a criterion for inclusion for participation and therefore nothing can be concluded from this factor. It would be interesting to study this factor further, specifically, observing young and old adults who are athletic and nonathletic and determining the effect of exercise on the motor component during performance of normal daily living tasks.

Choice did make a difference when considering the process measure. When a subject was attending, planning, organizing, and adapting a task, he or she performed optimally when he or she perceived control. This finding expands the findings of Perlmuter, Monty and their colleagues (Bailey et al., 1978; Chan et al., 1986; Monty \& Perlmuter, 1975; Perlmuter \& Monty, 1977; Perlmuter et al., 1980; Savage et al., 1979) that were based primarily on a paired-associate learning paradigm. Thus, perceived choice 
enhances performance on both laboratory and nonlaboratory tasks.

It has been suggested that the element of control may account for differences in performance between young and old adults rather than age itself. The findings in this study did not support this idea. Under the control enhancing condition, subjects did indeed perform significantly better, but this was equally true for young and old adults. Further, because there was no interaction effect between choice, age, and task, this study does not support the notion, proposed by Perlmuter and Monty (1986), that the lack of perceived control can lead to an exaggeration of the magnitude of age-related decline in cognitive performance.

It was hypothesized that there might be a choice by task interaction, because, when given a choice of familiar tasks of similar attractiveness, subjects may perceive more control, be more motivated, and therefore demonstrate higher performance.

Conversely, when offered a choice of unfamiliar tasks, individuals may have a more difficult time making a meaningful choice, thereby perceiving less control and demonstrating the same level of performance on both the chosen unfamiliar and the assigned unfamiliar tasks. This hypothesis is based on previous findings 
(Burger et al., 1983), suggesting individuals react negatively to perceived control in they lack competence. The results of this study did not support this idea. Although the subjects selected the unfamiliar tasks based only on the contrived names of the tasks, they still performed better on the chosen tasks then on the assigned tasks. These results do, however, concur with the concept that beneficial effects of choice occur if the choices are between similar alternatives (Harvey \& Johnston, 1973; Perlmuter \& Monty, 1977; Savage et al., 1979). In this case, even though the names of unfamiliar tasks were meaningless and gave little clue to the purpose or construct of the task, they were similar alternatives and thus, the subjects may have felt the opportunity for choice gave them more control over their performance.

However, there is also another possibility for these results. Two studies (Chan et al., 1986; Perlmuter et al., 1980) found that for subjects who perceived control and demonstrated improved performance, the beneficial effects generalized to other tasks in which there was no choice. As subjects could make an "informed" choice on the familiar activities of daily living, the beneficial effect of the perceived control may have generalized to the 
unfamiliar tasks, because they were chosen at the same time and were performed in the same session (though not in the same order). Another study that used different subjects for all conditions (i.e., a between-subject design) would be needed to rule out this possibility. Further, one cannot necessarily assume subjects felt incompetent with regard to their ability to follow task instructions.

Finally, the results of the study demonstrated individual variability of performance. Although there was a significant age effect, the scatterplots of both the motor and process measures indicate that some of the older subjects did just as well or better than some of the younger subjects. An important study would be to ask individuals to perform the same activities over a period of time and thus examine how performance evolves over the lifespan. In such a longitudinal study, one would examine the skill items individually and attempt to understand specific processes in the pattern of change in performance. Such a study may explain some of the subject variability in this study. For example, do the older adults who performed lower than the young adults do so because they have always had lower ability or at some point in time did they lose specific abilities? 
Another interesting and related question would be whether the motor and process abilities during activities of daily living decline linearly throughout the life-span or begin to decline with the onset of old age. This could be tested by including a group of middle age subjects performing the same types of tasks.

In summary, older adults demonstrated poorer performance on unfamiliar, meaningless tasks and on tasks of daily living which they rated as very familiar and were performed in their home environments. Thus, this study supports the hypothesis that older adults demonstrated age-related decline even with activities that take motivational, experiential, and ecological validity components into account. Results also support the concept that perceived control can improve performance, but not differentially for older adults; that is, young and old adults both had improved performance when given their choice of tasks. These findings support the external validity of laboratory studies that find the performance of older adults to be below the level of young adults. 
Abramson, L.Y., Seligman, M.E.P., \& Teasdale, J.D. (1978). Learned helplessness in humans: Critique and reformulation. Journal of Abnormal Psychology, 87, 49-74.

Adams, C.C. \& Rebok. G.W. (1982-3). Planfulness and problem solving in older adults. International Journal of Aging and Human Development, 16, 271-281.

Akiyama, M.M, Akiyama, A., \& Goodrich, G.C. (1985). Spatial development across the life span. International Journal of Aging and Human Development, 21, 175-185.

Amrhein, P.C., Stelmach, G.E., \& Goggin, N.L. (1991). Age differences in the maintenance and restructuring of movement preparation. Psychology and Aging, 6, 451-466.

Bailey, S.E., Perlmuter, L.C., Karsh, R., \& Monty, R.A. (1978). Choices for others and the perception of control. Motivation and Emotion, 4, 191-200.

Baltes, P.B. (1987). Theoretical propositions of life-span development psychology: On the dynamics between growth and decline, Developmental Psychology, 23, 611-626.

Baltes, P.B. \& Willis, S.L. (1982). Plasticity and enhancement of intellectual functioning in old age. In F.I.M. Craik \& S. Trenub (Eds.), Aging and Cognitive Processes (pp. 353-385). New York: Plenum Press.

Bandura, A. (1981). Self-referent thought: A developmental analysis of self-efficacy. In J. Flavell \& L. Ross (Eds.), Social Cognitive Development. New York: Cambridge University Press.

Baylor, A.M. \& Spirduso, W.W. (1988). Systematic aerobic exercise and components of reaction time in older women. Journal of Gerontology: Psychological Sciences, 43, P121-P126. 
Berg, C., Hertzog, C., \& Hunt, E. (1982). Age differences in the speed of mental rotation. Developmental Psychology, 18, 95-107.

Bernspång, B. \& Fisher, A.G. (1993). Motor and process ability of persons with right or left CVA. Manuscript in preparation.

Bosman, E.A. (1993). Age-related differences in the motoric aspects of transcription typing skill. Psychology and Aging, 8, 87-102.

Botwinick, J. (1984). Aging and Behavior, 3rd edition. New York: Springer.

Botwinick, J. \& Thompson, L.W. (1987). Age difference in reaction time: An artifact? The Gerontologist, 8, 25-27.

Bruce, P.R. \& Herman, J.F. (1986). Adult age differences in spatial memory: Effects of distinctiveness and repeated experience. Journal of Gerontology, 4, 774-777.

Burger, J.M., Brown, R., \& Allen, C.K. (1983). Negative reactions to personal control. Journal of Social and Clinical Psychology, 1, 322-342.

Cerella, J. (1990). Aging and information-processing rate. In J.E. Birren \& K.W. Schaie (Eds.), Handbook of the Psychology of Aging (pp. 201-221). New York: Academic Press, Inc.

Chan, F., Karbowski, J., Monty, R.A., \& Perlmuter, L.C. (1986). Performance as a source of perceived control. Motivation and Emotion, 10, 59-70.

Clarkson-Smith, L. \& Hartley, A.A. (1989). Relationships between physical exercise and cognitive abilities in older adults. Psychology and Aging, 4, 183-189.

Craik, F.I.M. \& Byrd, M. (1982). Aging and cognitive deficits. In Craik, F.I.M. \& Trenub, S. (Eds.), Aging and Cognitive Processes (pp. 191-209). New York: Plenum Press. 
Craik, F.I.M., Byrd, M., \& Swanson, J.M. (1987). Patterns of memory loss in three elderly samples. Psychology and Aging, 2, 79-86.

Crossley, M. \& Hiscock, M. (1992). Age-related differences in concurrent-task performance of normal adults: Evidence for a decline in processing resources. Psychology and Aging, 7, 499-506.

Denney, N.W. (1982). Aging in cognitive changes. In B.B. Wohlman, (Ed.), Handbook of Developmental Psychology (pp. 807-827). Englewood Cliffs, NJ: Prentice-Hall.

Denney, N.W. (1985). A review of life span research with the twenty questions task: a study of problem solving ability. Aging and Human Development, 21, 161-173.

Denney, N.W. \& Palmer, A.M. (1981). Adult age differences on traditional and practical problem-solving measures. Journal of Gerontology, 30, 323-328.

Denney, N.W. \& Pearce, K.A. (1989). A developmental study of practical problem solving in adults. Psychology and Aging, 4, 438-442.

Denney, N.W., Tozier, T.L., \& Schlotthauer, C.A. (1992). The effect of instructions on age differences in practical problem solving. Journal of Gerontology: Psychological Sciences, 47, P142-145.

Dickerson, A.E. (1990). Age Differences in Functional Performance: Deficits or Artifacts? Unpublished master's thesis. Florida International University, Miami, FL.

Dickerson, A.E. \& Fisher, A.G. (1993). Age differences in functional performance. American Journal of Occupational Therapy, 47, 686-692.

Dickerson, A.E. \& Fisher, A.G. (in press). Culture-relevant functional performance assessment of the Hispanic elderly. Occupational Therapy Journal of Research. 
Dixon, R.A., Kurzman, D., \& Friesen, I.C. (1993). Handwriting performance in younger and older adults: Age, familiarity, and practice effects. Psychology and Aging, 8, 360-370.

Doble, S.E., Fisher, A.G., Fisk, J.D. \& MacPherson, K.M. (1992). Validation of the Assessment of Motor and Process Skills (AMPS) with Elderly Adults with Dementia. Final report to the Alzheimer's Association. Halifax, Nova Scotia: Dalhousie University.

Fisher, A.G. (1990). Assessment of Motor and Process Skills (research version 6.1). Unpublished test manual, Department of Occupational Therapy, Colorado State University, Fort Collins, Colorado.

Fisher, A.G. (1993). The assessment of IADL motor skills: An application of many-faceted Rasch analysis. American Journal of Occupational Therapy, 47, 319-338.

Fisher, A.G. (1994). Assessment of Motor and Process Skills (research version 7.0). Unpublished test manual, Department of Occupational Therapy, Colorado State University, Fort Collins, Colorado.

Fisher, A.G. (in press). Development of a functional assessment that adjusts ability measures for task simplicity and rater leniency. In M. Wilson (Ed.), Objective Measurement: Theory into Practice. (Vol. 2). Norwood, NJ: Ablex.

Fisher, A.G., Bryze, K. A., Granger, C. V., Haley, S.M., Hamilton, B.B., Heinemann, A.W., Puderbaugh, J.K., Linacre, J.M., Ludlow, L.H., McCabe, M.A., \& Wright, B.D. (in press). Applications of Rasch analysis to the development of functional assessments. International Journal of Educational Research.

Fisher, A.G. Lui, Y., Velozo, C.A., \& Pan, A.W. (1992). Cross-cultural assessment of process skills. American Journal of Occupational Therapy, 46, 876-885. 
Fleming, C.C. \& Lopez, M.A. (1981). The effects of perceived control on the paired-associate learning of elderly persons. Experimental Aging Research, 7, 71-77.

Foos, P.W. (1989). Age differences in memory for two common objects. Journal of Gerontology: Psychological Sciences, 44, P178-180.

Fullerton, A.M. (1988). Adult age differences in solving series problems requiring integration of old and new information. Aging and Human Development, 26, 147-155.

Gaylord, S.A. \& Marsh, G.R. (1975). Age differences in the speed of a spatial cognitive process. Journal of Gerontology, 30, 674678.

Geary, D.C., Frensch, P.A., \& Wiley, J.G. (1993). Simple and complex mental subtraction: Strategy choice and speed-of-processing differences in younger and older adults. Psychology and Aging, 8, 242-256.

Grant, E.A., Storandt, M., \& Botwinick, J. (1978). Incentive and practice in the psychomotor performance of the elderly. Journal of Gerontology, 33, 413-415.

Guralnik, J.M., Branch, L.G., Cummings, S.R., \& Curb, J.D. (1989). Physical performance measures in aging research. Journal of Gerontology, 44, M141-146.

Hale, S., Myerson, J., \& Wagstaff, D. (1987). General slowing of nonverbal information processing: evidence for a power law. Journal of Gerontology, 42, 131-136.

Hambleton, R.K. (1989). Principles and selected applications of item response theory. In R.L. Linn (Ed.), Educational Measurement (pp147-200). New York: American Council on Education and Macmillan Publishing. 
Hartley, A. (1981). Adult age differences in deductive reasoning processes. Journal of Gerontology, 36, 700-706.

Hartley, A.A. \& Anderson, J.W. (1983). Task complexity and problemsolving performance in younger and older adults. Journal of Gerontology, 38, 72-77.

Harvey, J.H. \& Johnston, S. (1973). Determinants of the perception of choice. Journal of Experimental Social Psychology, 9, 164179.

Hasher, L. \& Zacks, R. (1979). Automatic and effortful processes in memory. Experimental Psychology, 108, 356-388.

Hawkins, H.L., Kramer, A.F., \&Capaldi, D. (1992). Aging, exercise, and attention. Psychology and Aging, 7, 643-653.

Hess, T.M. \& Slaughter, S.J. (1986a). Aging effects on protype abstraction and concept identification. Journal of Gerontology. 41, 214-221.

Hess, T.A. \& Slaughter, S.J. (1986a). Specific exemplar retention and prototype abstraction in young and old adults. Psychology and Aging, 1, 202-207.

Hess, T.M. \& Wallsten, S.M. (1987). Age differences in the perception and learning of artistic categories. Psychology and Aging, 2, 243-253.

Hulicka, I.M. (1967). Age differences in retention as a function of interference. Journal of Gerontology, 22, 180-184.

Isaac, S. \& Michael, W.B. (1984). Handbook in Research and Evaluation. San Diego: Edits Publishers.

Jacewicz, M.W. \& Hartley, A.A. (1987). Age differences in the speed of cognitive operations: resolution of inconsistent findings. Journal of Gerontology, 42, 86-88. 
Kausler, D.H. (1982). Experimental Psychology and Human Aging. New York: Wiley.

Kausler, D.H. (1990). Motivation, human aging and cognitive performance. In J.E. Birren \& K.W. Schaie (Eds.), Handbook of the Psychology of Aging (pp. 171-182). New York: Academic Press, Inc.

Kirasic, K.C. (1990). The Effects of age and environmental familiarity on adults' spatial problem-solving performance: Evidence of a hometown advantage. Experimental Aging Research, 15, 181-187.

Kirasic, K.C. (1991). Spatial cognition and behavior in young and elderly adults: Implications for learning new environments. Psychology and Aging, 6, 10-18.

Kirasic, C.C. \& Allen, G.L. (1985). Aging, spatial performance and spatial competence. In Charness, N. (Ed.), In Aging and Human Performance (pp. 191-217). New York: Wiley.

Labouvie-Vief, G. \& Gonda, J.N. (1976). Cognitive strategy training and intellectual performance in the elderly. Journal of Gerontology, 31, 327-332.

Lachman, M.E. (1986). Personal control in later life: Stability, change, and cognitive correlates. In M.M. Baltes \& P.B. Baltes (Eds.), Psychology of Aging and Control (pp. 207-236). Hillsdale, NJ: Lawrence Erlbaum Associates.

Lachman, M.E. \& Jelalian, E. (1984). Self efficacy and attributions for intellectual performance in young and elderly adults. Journal of Gerontology, 39, 577-582.

Lachman M.E. \& Leff, R. (1989). Perceived control and intellectual functioning in the elderly: A 5-year longitudinal study. Developmental Psychology, 25, 722-728. 
Lachman, M.E., Baltes, P., Nesselroade, J.R., \& Willis, S.L. (1982).

Examination of personality-ability relationships in the elderly:

The role of the contextual (interface) assessment mode.

Journal of Research in Personality, 16, 485-501.

Lachman, M.E., Steinberg, E.S., \& Trotter, S.D. (1987). Effects of control beliefs and attributions on memory self-assessments and performance. Psychology and Aging, 2, 266-271.

Langer, E.J. (1979). The illusion of incompetence. In L.C. Perlmutter \& R.A. Monty (Eds.) Choice and Perceived Control (pp. 301-314). Hillsdale, NJ: Lawrence Erlbaum Associates.

Langer, E.J. \& Rodin, J. (1976). The effects of choice and enhanced personal responsibility for the aged: A field experiment in an institutional setting. Journal of Personality and Social Psychology, 34, 191-198.

Linacre, J.M. (1989). FACETS: Computer program for many-faceted Rasch measurement. Chicago: MESA.

Lindenberger, U., Kliegl, R., \& Baltes, P.B. (1992). Professional expertise does not eliminate age differences in imagery-based memory performance during adulthood. Psychology and Aging, 7, 585-593.

Levy, L.L. (1986). Sensory Changes and Compensation. In L.I. Davis \& M. Kirkland (Eds.), The Role of Occupational Therapy with the Elderly (pp. 49-68). Rockville, Maryland: American Occupational Therapy Association.

Light, K.E. \& Spirduso, W.W. (1990). Effects of adult aging on the movement complexity factor of response programming. Journal of Geronotology: Psychological Sciences, 45, P107P109. 
Lunz, M.E. \& Stahl, J.A. (1990). Judge consistency an severity across grading periods. Evaluation and the Health Professions, 13, 425-444.

Macht, M. \& Buschke, H. (1983). Age differences in cognitive effort in recall. Journal of Gerontology, 38, 695-700.

Magalhães, L.C., Fisher, A.G., Bernspång, B., \& Linacre, J.M. (1993). Developing the Assessment of Motor and Process Skills as a cross-cultural evaluation of IADL ability. Manuscript submitted for publication.

Meeuwsen, H.J., Sawicki, T.M., \& Stelmach, G.E. (1993). Improved foot position sense as a result of repetitions in older adults. Journal of Geronotology: Psychological Sciences, 48, P137P141

Mitchell, D.B. \& Perlmutter, M. (1986). Semantic activation and episodic memory: Age similarities and differences. Developmental Psychology, 22, 86-94.

McCrae, R.R., Arenberg, D., \& Costa, P.T. (1987). Declines in divergent thinking with age: Cross sectional, longitudinal, and cross sequential analysis. Psychology and Aging, 2, 130-137.

McDowd, J.M. (1986). The effects of age and extended practice on divided attention performance. Journal of Gerontology, 41, 764-769.

McDowd, J.M. \& Birren, J.E. (1990). Aging and attentional processes. In.J.E. Birren \& K.W. Schaie (Eds.), Handbook of the Psychology of Aging (pp. 222-233). New York: Academic Press, Inc.

Monty, R.A. \& Perlmuter, L.C. (1975). Persistence of the effects of choice on paired-associate learning. Memory and Cognition, 3, 183-187. 
Monty, R.A., Rosenberger, M.A., \& Perlmuter, L.C. (1973). Amount and locus of choice as sources of motivation in paired-associate learning. Journal of Experimental Psychology, 97, 16-21.

Monty, R.A., Geller, E.S., Savage, R.E., \& Perlmuter, L.C. (1979). The freedom to choose is not always so choice. Journal of Experimental Psychology: Human Learning and Memory, 5, 170178.

Morrow, D.G., Leirer, V.O., \& Altieri, P.A. (1992). Aging, expertise, and narrative processing. Psychology and Aging, 7, 376-388.

Morrow, D.G., Leirer, V.O., Altieri, P.A., \& Fitzsimmons, C. (1994).

When expertise reduces age differences in performance.

Pschology and Aging, 9, 134-148.

Morse, D.K. (1993). Does variability increase with age? An archival study of cognitive measures. Psychology and Aging, 8, 156164.

Park, D.C., Smith, A.D., Morrell, R.W., Puglisi, J.T., \& Dudley, W.N. (1990). Effect of contextual integration recall of pictures by older adults. Journal of Gerontology, 45, 52-57.

Perimuter, L.C. \& Langer, E.J. (1982). The effects of behavioral monitoring on the perception of control. Clinical Gerontolgist, $1,37-43$.

Perlmuter, L.C. \& Monty, R.A. (1977). The importance of perceived control: Fact or fantasy? American Scientist, 65, 759-765.

Perlmuter, L.C. \& Monty, R.A. (1989). Motivation and aging. In L.W. Poon, D.C. Rubin, \& B.A. Wilson (Eds.), Everyday Cognition in Adulthood and Late Life (pp. 373-393). New York: Cambridge University Press. 
Perlmuter, L.C., Monty, R.A., \& Chan, F. (1986). Choice, control, and cognitive functioning. In M.M. Baltes \& P.B. Baltes (Eds.), The Psychology of Aging and Control (pp. 91-118). Hillsdale, NJ: Lawrence Erlbaum Associates.

Perlmuter, L.C., Monty, R.A., \& Cross, P.M. (1974). Choice as a disrupter of performance in paired-associate learning. Journal of Experimental Psychology,102, 170-172.

Perlmuter, L.C., Scharff, K., Karsh, R., \& Monty, R.A. (1980). Perceived control: A generalized state of motivation. Motivation and Emotion, 4, 35-45.

Plude, D.J. \& Hoyer, W.J. (1986). Age and the selectivity of visual information processing. Journal of Psychology and Aging, 1, 410.

Ponds, R.E., Brouwer, W.H., \& Wolffelaar, P.C. (1988). Age differences in divided attention in a simulated driving task. Journal of Gerontology, 43, 151-156.

Puglisi, T. (1986). Age related slowing in memory search for three dimensional objects. Journal of Gerontology, 41, 72-78.

Puglisi, J.T. \& Park, D.C. (1987). Perceptual elaboration and memory in older adults. Journal of Gerontology, 42, 160-162.

Puglisi, J.T., Park, D.C., Smith, A.D., \& Dudley, W.N. (1988). Age differences in encoding specificity. Journal of Gerontology, $43,145-150$.

Ratner, H.H., Schell, D.A., Crimmins, A., Mittelman, D., \& Baldinelli, C. (1987). Changes in adults prose recall: Aging or cognitive demands. Developmental Psychology, 23, 521-525.

Reich, J.W. \& Zautra, A.J. (1990). Dispositional control beliefs and the consequences of a control-enhancing intervention. Journal of Gerontology, 45, pp. 46-51. 
Rhee, C. \& Gatz, M. (1993). Cross-generational attributions concerning locus of control beliefs. International Journal of Aging and Human Development, 37, 153-161.

Robinson, K. \& Ross, S.M. (1987). Incentives as a treatment variable for facilitation performance of elderly adults on concrete Piagetian tasks. International Journal of Behavioral Development, 10, 501-508.

Rodin, J. \& Langer, E. (1980). Aging labels: The decline of control and the fall of self esteem. Journal of Social Issues, 36, 1229.

Rubenstein, L.Z., Schairer, C., Wieland, G.D., \& Kane, R. (1984).

Systematic biases in functional status assessment of elderly adults: Effects of different data sources. Journal of Gerontology, 39, 686-691.

Rybash, J.M., Hoyer, W.J., \& Roodin, P.A. (1986). Adult Cognitive and Aging. New York: Pergamon Press.

Ryden, M.B. (1984). Morale and perceived control in institutional elderly. Nursing Research, 33, 130-136.

Salthouse, T.A. (1984). Effects of age and skill in typing. Journal of Experimental Psychology: General, 113, 345-371.

Salthouse, T.A. (1985a). Speed of behavior and its implications for cognition. In J.E. Birren \& K.W. Schaie (Eds.) Handbook of the Psychology of Aging (pp. 400-426). New York: Van Nostrand Reinhold.

Salthouse, T.A. (1985b). A Theory of Cognitive Aging. New York: Elsevier Science Publishing Company, Inc.

Salthouse, T.A. (1987). Adult age differences in integrative spatial ability. Psychology and Aging, 2, 254-260. 
Salthouse, T.A. (1990). Cognitive competence and expertise in aging. In J.E. Birren \& K.W. Schaie (Eds), Handbook of the Psychology of Aging (pp. 310-319). New York: Academic Press, Inc.

Salthouse, T.A. (1991). Age and experience effects on the interpretation of orthographic drawings of three-dimensional objects. Psychology and Aging, 6, 426-433.

Salthouse, T.A. (1991). Theoretical perspectives on cognitive aging. Hillsdale, NJ: Lawrence Erlbaum Associates.

Salthouse, T.A. (1993). Speed mediation of adult age differences in cognition. Psychology and Aging, 29, 722-738.

Salthouse, T.A. (1994). The nature of the influences of speed on adult age differences in cognition. Psychology and Aging, 30, 240-259.

Salthouse, T.A. \& Mitchell, D.R.D. (1990). Effects of Age and naturally occurring experience on spatial visualization performance. Developmental Psychology, 26, 845-854.

Salthouse, T.A. \& Prill, K.A. (1987). Inferences about age impairments in inferential reasoning. Psychology \& Aging, 2, 43-51.

Salthouse, T.A. \& Somberg, B.L. (1982). Skilled performance: Effects of adult age and experience in elementary processes. Journal of Experimental Psychology, General, 111, 176-207.

Salthouse, T.A., Babcock, R.L., Skovronek, E., Mitchell, D.R.D., \& Palmon, R. (1990). Age and experience effects in optical visualization. Developmental Psychology, 26, 128-136. 
Savage, R.E., Perimuter, L.C., \& Monty, R.A. (1979). Effect of reduction in the amount of choice and the perception of control on learning. In L.C. Perlmutter \& R.A. Monty (Eds.), Choice and Perceived Control (pp. 91-106). Hillsdale, NJ: Lawrence Erlbaum Associates.

Schulz, R. (1980). Aging and control. In J. Garber \& M.E.P.Seligman (Eds.) Human Helplessness: Theory and Applications (pp. 261277). New York: Academic Press.

Schulz, R. \& Hanusa, BH. (1979). Environmental influences on the effectiveness of control and competence-enhancing interventions. In L.C. Perlmutter \& R.A. Monty (Eds.) Choice and Perceived Control (pp. 315-337). Hillsdale, NJ: Lawrence Erlbaum Associates.

Schulz, R., Heckhausen, J.L., \& Locher, J.L. (1991). Adult development, control, and adaptive functioning. Journal of Social Issues, 47, 177-196.

Sharps, J.J. \& Gollin, E.S. (1987). Memory for object locations in young and elderly adults. Journal of Gerontology, 42, 336-341.

Silverstein, B. Kilgore, K., \& Fisher, W. (1989). Implementing patient tracking systems and using functional assessment scales. Center for Rehabilitation Outcome Analysis monograph series on issues and methods in rehabilitation outcome analysis, 1. Wheaton IL: Marianjoy Rehabilitation Center.

Simon, J.R. \& Pouraghabagher, A.R. (1978). The effect of aging on the stages of processing in a choice reaction time task. Journal of Gerontology, 33, 553-561.

Spirduso, W.W. (1980). Physical fitness, aging, and psychomotor speed: a review. Journal of Gerontology, 35, 850-865.

Spirduso, W.W., \& MacRae, P.G. (1990). Motor performance and aging. In J.E. Birren \& K.W. Schaie (Eds.), Handbook of the Psychology of Aging (pp. 183-200). New York: Academic Press, Inc. 
Stelmach, G.E., Amrhein, P.C., \& Goggin, N.C. (1988). Age differences in bimanual coordination. Journal of Gerontology, 43, 18-23.

Stelmach, G.E., Goggin, N.L., \& Garcia-Colera, A. (1986). Movement specification time with age. Experimental Aging Research, 13, 39-46.

Stelmach, G.E., Teasdale, N., DiFabio, R.P., \& Phillips, J. (1989). Age related decline in postural control mechanisms. International Journal and Human Development, 29, 205-223.

Stine, E.A.L., Lachman, M.E., \& Wingfield, A. (1993). The roles of perceived and actual control in memory for spoken language. Educational Gerontology, 19, 331-349.

Taub, H.A., Baker, M.T., \& Kline, G.E. (1982). Perceived choice of prose materials by young and elderly adults. Educational Gerontology, 8, 447-453.

Teasdale, N., Stelmach, G.E., \& Breunig, A. (1991). Postural sway characteristics of the elderly under normal and altered visual and support surfaces conditions. Journal of Gerontology: Biological Sciences, 46, B238-244.

Till, R. (1985). Verbatim and inferential memory in young and elderly adults. Journal of Gerontology, 40, 316-323.

Weisz, J.R. (1983). Can I control It? The pursuit of veridical answers across the life span. In P. B. Baltes \& O.G. Brim (Eds.), Life-Span Development and Behavior (pp. 23-300). New York: Academic Press, Inc.

Welford, A.T. (1984). Psychomotor performance. Annual Review of Gerontology and Geriatrics, 4, 237-273.

Wickens, C.D. \& Braune, R. \& Stokes, A. (1987). Age differences in the speed and capacity of information processing: 1 . a dual task approach. Psychology and Aging, 2, 70-78. 
Woollacott, Shumway-Cook, A., \& Nashner, L.M. (1986). Aging and posture control changes in sensory organization and muscular coordination. Aging and Human Development, 23, 97-115.

Wright, R.E. (1981). Aging, divided attention, and processing capacity. Journal of Gerontology, 36, 605-614.

Wright, B.D. \& Masters, G.N. (1982). Rating Scale Analysis. Chicago: MESA Press.

Wright, B.D. \& Stone, M.H. (1979). Best Test Design. Chicago: MESA Press.

Zacks, R.T., Hasher, L., Doren, B., Hamm, V., \& Attig, M.S. (1987). Encoding and memory of explicit and implicit information. Journal of Gerontology, 42, 418-422. 
Table 1

Results of Familiar Task Survey

Percentage Selected as Choice Order

$\begin{array}{lccccccc}\text { Tasks } & \text { 1st } & \text { 2 nd } & \mathbf{3} \text { rd } & \mathbf{4 t h} & \mathbf{5} \mathbf{t h} & \text { 6th } & \begin{array}{l}\text { Not } \\ \text { Selected }\end{array} \\ \text { Set a table } & 10.2 & 2.0 & 8.2 & .7 & 4.8 & 10.2 & 63.9 *\end{array}$

$\begin{array}{lllllllll}\text { French toast } & 5.4 & 2.7 & 4.1 & 7.5 & 4.8 & 5.4 & 70.1 \text { * }\end{array}$

$\begin{array}{llllllll}\text { Egg,toast, bev } & 15.0 & 7.5 & 9.5 & 5.4 & 3.4 & 2.0 & 57.1\end{array}$

$\begin{array}{llllllll}\text { Meat,egg,toast } & 2.0 & 3.4 & 3.4 & 4.1 & 4.1 & 0.0 & 83.0 \text { * }\end{array}$

$\begin{array}{llllllll}\text { Omelette } & 7.5 & 6.1 & 5.4 & 6.8 & 8.8 & 6.8 & 58.5\end{array}$

$\begin{array}{llllllll}\text { Plant care } & 4.1 & 4.8 & 8.8 & 5.4 & 5.4 & 11.6 & 59.9\end{array}$

$\begin{array}{lllllllll}\text { Repot plant } & 7.5 & 2.7 & 6.1 & 3.4 & 2.7 & 6.1 & 71.4 \text { * }\end{array}$

$\begin{array}{lllllllll}\text { Iron shirt } & 20.4 & 8.2 & 4.8 & 12.2 & 6.8 & 8.2 & 39.5\end{array}$

$\begin{array}{lllllllll}\text { Fruit salad } & 2.7 & 8.2 & 5.4 & 10.9 & 8.8 & 4.1 & 59.9\end{array}$

$\begin{array}{lllllllll}\text { Green } & \text { salad } & 18.4 & 18.4 & 11.6 & 10.9 & 9.5 & 6.8 & 24.5\end{array}$

$\begin{array}{llllllll}\text { Vaccu um } & 4.8 & 10.2 & 11.6 & 6.8 & 9.5 & 6.1 & 51.0\end{array}$

$\begin{array}{lllllllll}\text { Tuna sandwich } & 14.3 & 13.6 & 8.8 & 10.2 & 8.8 & 8.8 & 35.2\end{array}$

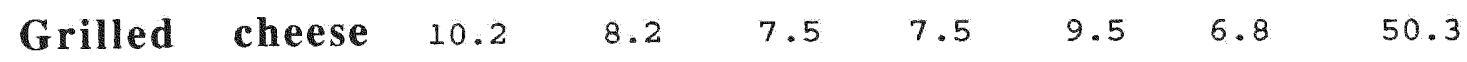

*Note: These tasks had the highest percentage of not being selected, and thus were eliminated from the study at this point. 
Table 2

Number of Completed Chosen and Assigned Tasks

Performed by Young and Old Adults

\begin{tabular}{lccccc}
\hline & \multicolumn{3}{c}{ Young } & \multicolumn{2}{c}{ Old } \\
\cline { 2 - 6 } Tasks & & Chosen & Assigned & Chosen & Assigned \\
Green Salad & 11 & 12 & 10 & 9 \\
Grilled Cheese & 19 & 10 & 13 & 7 \\
Scrambled Egg & 9 & 11 & 8 & 10 \\
Fruit Salad & 9 & 11 & 13 & 12 \\
Tuna Salad & 11 & 10 & 7 & 14 \\
Egg, Toast, Bev & 3 & 13 & 11 & 10 \\
Canned Tent & 9 & 12 & 10 & 12 \\
Cheeriopotato & 14 & 9 & 8 & 14 \\
PVC Lunch & 4 & 16 & 6 & 8 \\
Hold That Water & 12 & 10 & 12 & 9 \\
Hang Them High & 8 & 13 & 7 & 12 \\
Dark Secret & 15 & 6 & 19 & 7 \\
\hline & & & & & \\
\hline
\end{tabular}


Table 3

Means and Standard Deviations for Familarity of

Tasks for Young and Old Adults

\begin{tabular}{|c|c|c|c|c|}
\hline & $\begin{array}{l}\text { F a mil a r } \\
\text { Chosen }\end{array}$ & $\begin{array}{l}\text { Familar } \\
\text { Assigned }\end{array}$ & $\begin{array}{c}\text { Un f a m il a r } \\
\text { Chosen }\end{array}$ & $\begin{array}{c}\text { Unfamiliar } \\
\text { Assigned }\end{array}$ \\
\hline OId & $1.30(.48)$ & $1.29(.48)$ & $4.71(.60)$ & $4.70 \quad(.53)$ \\
\hline Young & $1.11(.25)$ & $1.19(.33)$ & $4.61(.73)$ & $4.74(.34)$ \\
\hline
\end{tabular}


Table 4

ANOVA Table for Familiarity of Task

SOURCE

DF

M S

F $\quad$ value

Between Subjects
A g e
1,57
.42
1.65
.204

Within Subjects

T a s k

Choice

Age by Task

Age by Choice

Task by Choice

Age by Task by Choice 1,57

1,57

1,57

1,57
707.54

.11

.19

.22

.01

.01
2157.11

$.001 *$

1,57

.78

.380

.07

.791

${ }^{*} \mathrm{p}<.001$ 
Table 5

Rasch Measurement Model Fit Statistics for Tasks

\section{Motor}

T a sk

Mean Square

$t$

\begin{tabular}{lllr}
\hline E a s y & Tuna Sandwich & 0.9 & -1 \\
& Egg, Toast, Beverage & 1.0 & 3 \\
& Canned Tent & 1.2 & 3 \\
& Grilled Cheese & 1.2 & 2 \\
Toss Salad & 0.9 & -1 \\
Dark Secret & 1.0 & 0 \\
Omlette, Toast, Beverage & 1.0 & 0 \\
Fruit Salad & 1.1 & 1 \\
& Cheeriopotato & 1.0 & 0 \\
& PVC Lunch & 1.0 & 0 \\
& Hang Them High & 1.1 & 1 \\
H ard dold That Water & 1.1 & 1
\end{tabular}

\section{Process}

$\begin{array}{lllr}\text { Eas y } & \text { Egg, Toast, Beverage } & 0.9 & -1 \\ & \text { Tuna Sandwich } & 1.0 & 0 \\ & \text { Grilled Cheese } & 1.0 & 0 \\ & \text { Fruit Salad } & 0.9 & -1 \\ & \text { Canned Tent } & 0.9 & -1 \\ & \text { Toss Salad } & 1.0 & 0 \\ & \text { Cheeriopotato } & 1.0 & 0 \\ & \text { Omlette, Toast, Beverage } & 0.9 & -1 \\ & \text { Hang Them High } & 1.0 & -1 \\ & \text { Hold That Water } & 1.1 & 2 \\ & \text { Dark Secret } & 1.0 & 1 \\ \text { Hard PVC Lunch } & 1.0 & 0\end{array}$


Table 6

Rasch Measurement Model Fit Statistics for Raters

Motor

\begin{tabular}{|c|c|c|c|}
\hline Rater & n & Mean Square & $t$ \\
\hline Rater 1 & 504 & 0.9 & -2 \\
\hline Rater 2 & 151 & 1.2 & 2 \\
\hline Rater 3 & 148 & 1.2 & 5 \\
\hline Rater 4 & 7 & 1.0 & 0 \\
\hline Rater 5 & 13 & 1.0 & 0 \\
\hline Rater 6 & 2 & 0.9 & 0 \\
\hline
\end{tabular}

$\mathrm{n}=$ number of observations scored.

Process

\begin{tabular}{|c|c|c|c|}
\hline Rater & $\mathbf{n}$ & Mean Square & $t$ \\
\hline Rater 1 & 504 & 1.0 & -2 \\
\hline Rater 2 & 151 & 1.0 & -1 \\
\hline Rater 3 & 148 & 1.1 & 4 \\
\hline Rater 4 & 7 & 0.9 & 0 \\
\hline Rater 5 & 13 & 0.9 & -1 \\
\hline Rater 6 & 2 & 0.7 & -1 \\
\hline
\end{tabular}

$\mathrm{n}=$ number of observations scored. 


\section{Table 7}

Means and Standard Deviations of Motor and Process Scores of Subjects Under All Conditions

\begin{tabular}{|c|c|c|c|c|}
\hline & $\begin{array}{l}\text { F a mi lar } \\
\text { Chosen }\end{array}$ & $\begin{array}{l}\text { Familar } \\
\text { Assigned }\end{array}$ & $\begin{array}{c}\text { Unfamilar } \\
\text { Chosen }\end{array}$ & $\begin{array}{r}\text { Unfamiliar } \\
\text { Assigned }\end{array}$ \\
\hline & $\mathrm{M} \quad(\mathrm{SD})$ & $\mathrm{M} \quad(\mathrm{SD})$ & $\mathrm{M} \quad(\mathrm{SD})$ & $\mathrm{M} \quad(\mathrm{SD})$ \\
\hline Old & $4.65(.57)$ & $4.58(.55)$ & $4.73(.45)$ & $4.62(.66)$ \\
\hline Young & $5.35(.39)$ & $5.29(.44)$ & $5.34(.40)$ & $5.34(.41)$ \\
\hline \multicolumn{5}{|l|}{ Process } \\
\hline Old & $4.85(.50)$ & $4.77(.44)$ & $4.83(.52)$ & $4.78 \quad(.44)$ \\
\hline Young & $5.27 \quad(.59)$ & $5.08(.41)$ & $5.23(.55)$ & $5.11(.37)$ \\
\hline
\end{tabular}


Table 8

ANOVA Table for Motor Scale

SOURCE

DF

M S

F

$P$ value

Between Subjects
A g e
1,57
27.74
60.83
$.001 *$

Within Subjects

T a sk

1,57

.10

.78

.382

Choice

1,57

.20

1.13

.292

Age by Task

1,57

.02

.13

.722

Task by Choice

1,57

.00

.00

.947

Age by Task by Choice 1,57

.04

.21

.648

$\star_{p}<.001$ 
Table 9

ANOVA Table for Process Scale

SOURCE

DF

M S

$\mathbf{F}$

$P$ value

\section{Between Subjects}

A g e

$$
1,57
$$

7.95

14.15

$.001 * *$

Within Subjects

T a sk

Choice

Age by Task

Age by Choice

Task by Choice

Age by Task by Choice 1,57

$$
1,57
$$

1,57

1,57

1,57

1,57

.03

.01

.70
.01

.924

4.40

$.040 *$

$*_{\mathrm{p}}<.05 ; * *_{\mathrm{p}}<.001$ 
Figure Caption

Figure 1. Scatterplot of motor skill scores by age. 


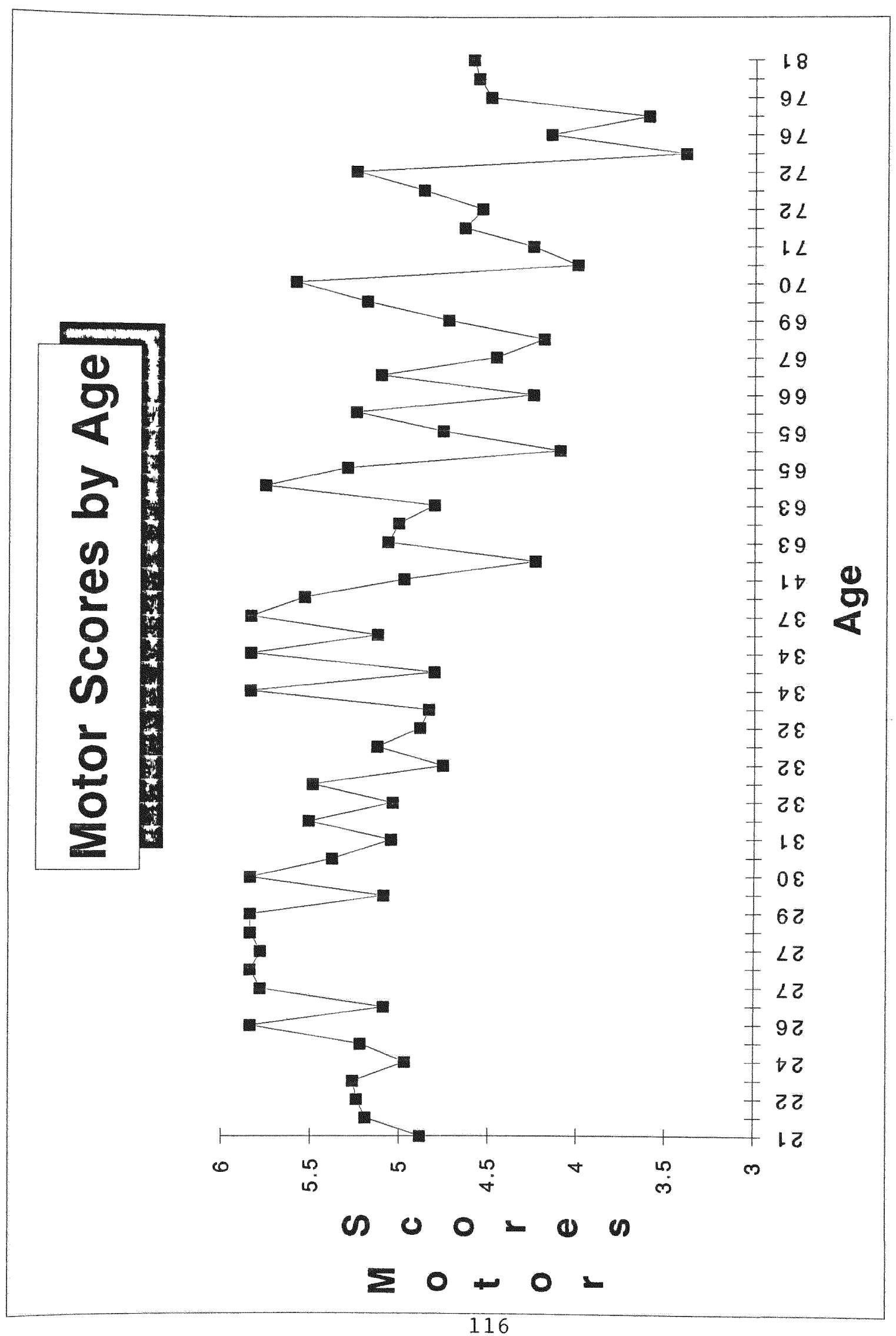


Figure Caption

Figure 2. Scatterplot of process skill scores by age. 


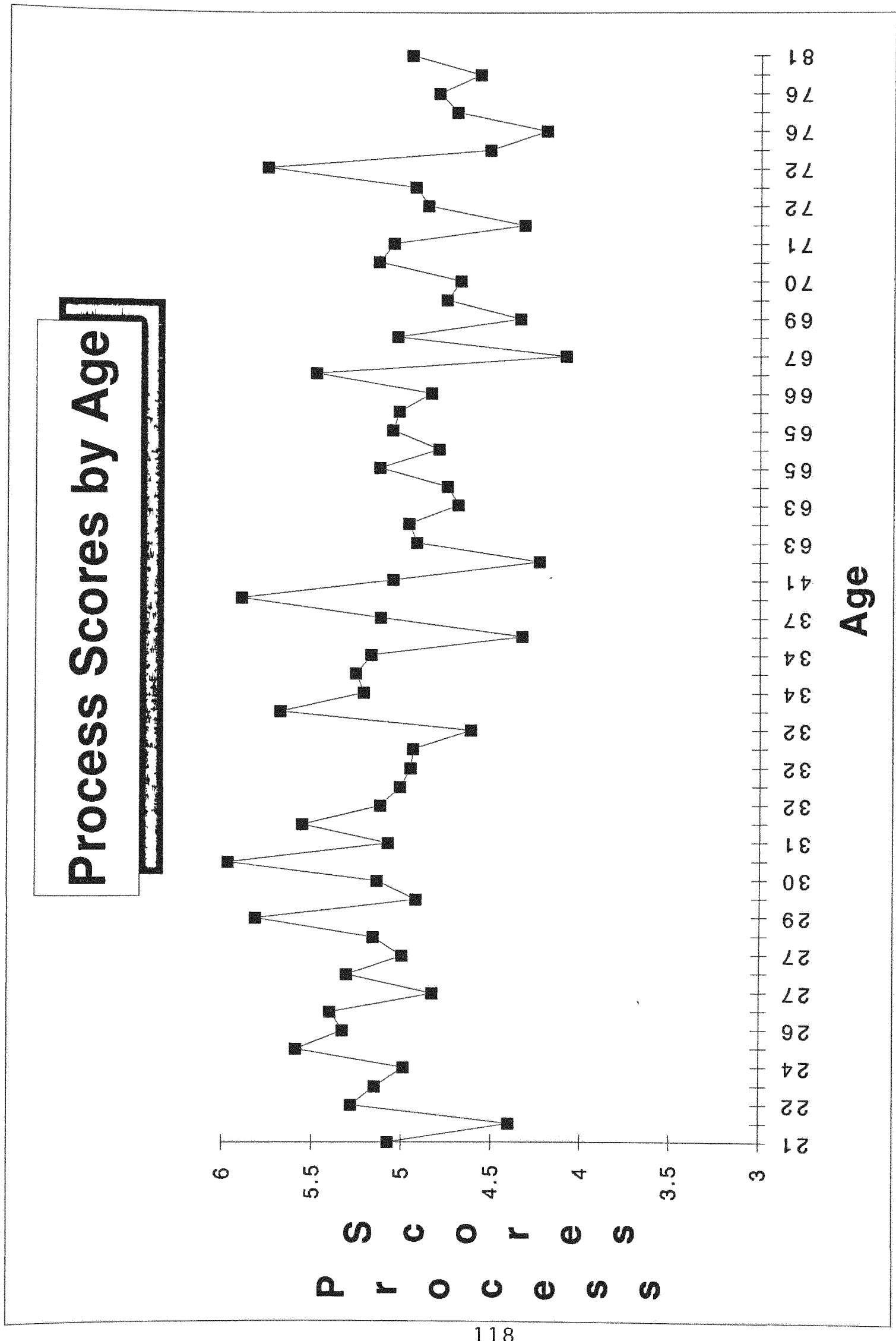




\section{Appendix A}

\section{MOTOR AND PROCESS SKILL ITEMS DEFINED}

\section{MOTOR SKILL ITEMS}

\section{Strength}

Moves - pushes, shoves, pulls, or drags along a supporting surface; includes opening doors and drawers. Pertains to the moving of objects that are not lifted (e.g., pushing or pulling on a cart, door, or drawer; dragging a heavy bag across the floor; or sliding a heavy pan along the counter top). Includes the ability to self-propel a wheelchair.

Lifts - raises or hoists objects off of supporting surface; includes moving an object that is lifted from one place to another, but without ambulation or moving from one place to another. Pertains to having enough strength to lift objects.

Reaches - stretches or extends the arm, and, when appropriate, the trunk to grasp or place objects that are out of reach. Pertains to the ability to effectively reach to the extend necessary in order to obtain objects. Where appropriate, this includes trunk movement.

Endures - persists and completes the task without evidence of fatigue, pausing to rest, or stopping to "catch ones breath."

\section{Posture And Mobility}

Transports - carries objects while ambulating or moving from one place to another (e.g., in a wheelchair). Pertains to the physical capacity to gather.

Stabilizes - steadies body, and maintains trunk control and balance while sitting, standing, or walking, while reaching, or while moving, lifting, pushing, or pulling objects; pertains to postural control during trunk or limb movements. 
Aligns - maintains the body weight evenly distributed over the base of support; implies an absence of asymmetries, flexed or stooped posture, or excessive leaning; pertains to body alignment that may be affected by structural or strength limitations.

Walks - ambulates on level surfaces; implies steadiness or an absence of shuffling, lurching, ataxia, etc.; includes the ability to turn around to change direction while walking.

Fine Motor Abilities And Subtle Postural Adjustments Bends - actively flexes, rotates, or twists the body in a manner and direction appropriate to the task; pertains to trunk mobility.

Coordinates - uses different parts of the body together or uses other body parts as an assist or stabilizer during bilateral motor tasks. Pertains to the physical capacity to hold, support, or stabilize objects during bilateral task performance.

Manipulates - uses dexterous grasp and release, as well as coordinate in-hand manipulation patters; pertains to skillful use of isolated finger movements when handling objects.

Flows - uses smooth, fluid, continuous, uninterrupted arm and hand movements. Pertains to the quality or refinement of motor execution; includes the absence of dysmetria, ataxia, tremor, rigidity, or stiffness of movement. Implies the ability to isolate movements.

Positions - positions body or wheelchair in relation to objects in a manner that promotes the use of efficient arm movements; pertains to the use of postural background movements appropriate to the task. Implies the absence of awkwardness of arm or body positions. Includes the ability to position the body or wheelchair appropriate to the task or movement pattern of the arm.

Calibrates - regulates or grades the force, speed, and extent of movements in the performance of a step or action; pertains to the amount of effort exerted or an expenditure of energy that is appropriate to the requirements of the action or step (e.g., not too 
much or too little).

Grips - pinches or grasps in order to grasp handles, to open fastenings and containers, or to remove coverings; relates to effectiveness of strength of pinch and grip.

\section{PROCESS SKILL ITEMS}

\section{Energy}

Attends - maintains focused attention throughout the task sequences; implies that the client can selectively focus attention on the task to be performed and appropriately allocated attentional resources to relevant aspects of the task and environment such that the client (a) is not distracted by extraneous auditory or visual stimuli, or (b) does not "over-attend" to stimuli or certain aspects of the task while disregarding others.

\section{Using Knowledge}

Chooses - selects appropriate tools and materials; implies an understanding of what to choose to gather. when specified prior to the initiation of the task, this also includes choosing and using the originally-agreed-on tools and materials.

Uses - employs tools and materials according to their intended purposes, or in a reasonable (including sanitary) fashion, given their intrinsic properties and the availability (or lack of availability) of other objects. Pertains to what or how the individual chooses to use tools and materials. Implies (a) having knowledge of the intended use or purpose of the object and an understanding of the object's capabilities, and (b) then using the object appropriately based on that knowledge and understanding. Includes using the proper tools for the proper job as well as using appropriate coverings and containers for restoration.

Handles - supports, stabilizes, and holds tools and materials in an appropriate manner given the circumstances of the situation and abilities of the individual; pertains to recognizing the need, and knowing how, to hold, stabilize, and support objects. Includes 
providing support to protect tools and materials from damage of falling (dropping).

Heeds - uses goal-directed task performance that is focused toward the completion of the specified task (i.e., the outcome originally agreed on); implies having a base understanding of the goal or purpose of the task, and an absence of behavior driven by environmental cues. Pertains to the ability to manage ones actions and behaviors in order to accomplish the specified task.

Inquires - seeks appropriate verbal/written information by asking questions or reading directions; includes asking questions related to where materials are located or how an action is performed.

Notices - responds appropriately to nonverbal environmental/perceptual cues (i.e., sound, smell, movement, heat, moisture, texture, shape, consistency) that provide feedback regarding task progression. Also pertains to responding appropriately to the presence of obstacles or the spatial arrangement of objects to one another. Implies noticing and, when indicated, making an appropriate response.

\section{Temporal Organization}

Initiates - starts or begins doing an action or step without hesitation; implies an end to decision-making.

Continues - performs an action sequence of a step without unnecessary interruption and as an unbroken, smooth progresssion; pertains to the continuing of a series of actions such that, once an action sequence is initiated, the individual continues on until it is completed.

Sequences - performs steps in an effective or logical order for efficient use of time and energy; implies an absence of randomness the ordering, or the inappropriate repetition ("re-ordering"), of steps.

Paces - maintains a rate or tempo of performance across the entire task; implies the maintenance of a rate that permits the completion 
of the task within a reasonable amount of time (i.e., lack of hypo- or hyperactivity, slowing over time, or an uneven pace). Pertains to the use of an effective rate of performance throughout the steps of the specified task.

Terminates - finishes or brings to completion single actions or steps without perseveration, inappropriate persistence, or premature cessation; implies stopping ongoing task performance in preparation for beginning the next action or step.

\section{Space And Objects}

Searches - looks for and locates tools and materials through the process of logical searching; pertains to the ability to investigate and look beyond the immediate environment in order to locate necessary or dispersed tools and materials (e.g., looking in, behind, on top of).

Gathers - collects together needed or misplaced tools and materials; pertains to (a) the collection of located supplies into the workspace for the performance of the task, (b) the collection and replacement of materials that have been spilled or dispersed, and (c) the retrieval of misplaced or fallen supplies.

Organize - logically positions or spatially arranges tools and materials in an orderly fashion in and between appropriate workspace(s) in order to facilitate ease of task performance.

Restores - returns/puts away tools and materials, and restores immediate workspace(s) to original condition (e.g., wiping counter clean and putting dirty dishes in the sink). Includes the closure and sealing of containers and coverings when restoring food items to their appropriate storage containers. Includes twisting or the folding under of plastic bags to seal; appropriate closure of bags does not require the use of a fastener.

\section{Adaptation}

Accommodates - modifies one's actions in anticipation of, or in response to, circumstances/problems that might arise in the course of action, or that require attention to avoid undesirable outcomes. 
The main focus of this behavior is that the individual changes the method with which he/she is performing the action sequence, or the manner in which he/she interacts with or handles tools and materials already in the workspace.

Adjusts - modifies environmental conditions in anticipation of, or in response to, circumstances/problems that arise in the course of action or that require attention to avoid undesireable outcomes. The main focus of this behavior is that the individual makes some change in the working environment by moving to a new workspace, bringing in or removing tools and materials from the present workspace, or by changing an environmental condition (i.e., light, temperature, etc.).

Navigates -modifies the movement pattern of the arm, body, or wheelchair to avoid or maneuver around existing obstacles that are encountered in the course of moving the arm, body, or wheelchair through space, and that require attention to prevent undesirable contact with obstacles (e.g., knocking over, stepping on, bumping into). Includes visually-guided arm movements and the ability to hold and maneuver an object around obstacles. The main focus of this behavior is that the individual makes some change in the movement trajectory of the arm or hand when reaching, the body when walking, or the wheelchair when moving around the environment.

Benefits - anticipates and prevents undesirable circumstances/problems from recurring or persisting. The main focus of this behavior is that the individual (a) recognizes what actions already have been completed, what problems already have occurred, or the potential for recurrence or persistence of a circumstance/problem; (b) learns from prior actions and adaptations, or from requested information; and (c) uses prior actions, adaptations, or information to alter the task progression accordingly. 
Appendix B

125 
DEMOGRAPHIC DATA

CLIENT:

TASK:

EXAMINER:

AGE:

DIAGNOSIS:

ETHNICITY:

$\begin{array}{ll}\text { WHITE/EUROPEAN } & \text { MIDDLE EASTERN } \\ \text { - HISPANICILATIN AM } & \text { BLACKIAFRICAN } \\ \text { - PACIFIC ISLANDER ORIENTALISE ASIAN } & \text { - OTHER }\end{array}$ GENDER: MALE _ FEMALE

AMPS MANUAL VERSION USED FOR SCOAING:

DATE OF ORIGINAL OBSERVATION

DATE OF SCOAIMG

SCORING FORMAT: DIRECT

VIDEOTAPE

ADAPTIVE EQUIPMENT: NONE

WHEEL CMAIR

WALKER

CANE _ OTHEA [SPECIFY)

SETTING: HOME/RESIDENCE - CUNIC

OBSERVATION TASK NUMBER: ONE__ TWO_ THREE__ OTHER (NO.)

CONSIOERING EVERTTHING YOU KNOW ABOUT THE CLENT, HOW WOULO YOU JUDGE THE CLENT'S OVERALL FUNCTIONAL ABIUTY?

- THE CLENT CAN/COULD UVE INDEPENDENTLY IN THE COMMUNTY

- THE CLIENT NEEDS/SHOULD HAVE MINIMAL ASSISTANCE/SUPERVISION TO UVE IN THE COAMUNTY

- THE CLIENT NeEDS/SHOULD HAVE MOdERATE TO MAXIMAL ASSISTANCE OR IS UNABLE TO LIVE IN THE COMMUNTY

SCORE SHEET

COMPETENT $=4$ QUESTIONABLE $=3$ INEFFECTVE $=2$ DEFICTT $=1$

POSTURE

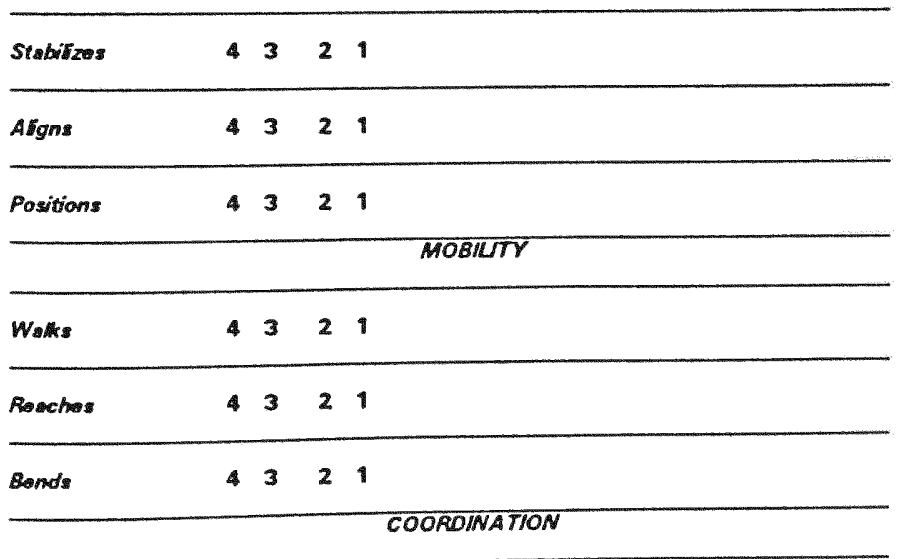

\begin{tabular}{llllll}
\hline Coordinetes & 4 & 3 & 2 & 1 \\
\hline Menipulates & 4 & 3 & 2 & 1 \\
\hline Flows & 4 & 3 & 2 & 1
\end{tabular}

STRENGTH AND EFFORT

\begin{tabular}{l|llll}
\hline Moves & 4 & 3 & 2 & 1 \\
\hline Transports & 4 & 3 & 2 & 1 \\
\hline Lits & 4 & 3 & 2 & 1 \\
\hline CaEbrate: & 4 & 3 & 2 & 1 \\
\hline Grips & 4 & 3 & 2 & 1 \\
\hline & 4 & 3 & 2 & 1 \\
\hline Enduns: & 4 & 3 & 2 & 1 \\
\hline \hline Paces: & 4 & 3 & 2 & 1 \\
\hline Attonds & & & USING KNOWLEDE \\
\hline
\end{tabular}

\begin{tabular}{|c|c|c|c|}
\hline Chooses & 4 & 3 & 2 \\
\hline Uses & 4 & 3 & 2 \\
\hline Handlog & 4 & 3 & 2 \\
\hline Hods & 4 & 3 & 2 \\
\hline Inquins & 4 & 3 & 2 \\
\hline
\end{tabular}

TEMPORAL ORGANIZATION

\begin{tabular}{lllll}
\hline Initistes & 4 & 3 & 2 & 1 \\
\hline Continues & 4 & 3 & 2 & 1 \\
\hline Soquenos & 4 & 3 & 2 & 1 \\
\hline Teminates & 4 & 3 & 2 & 1 \\
\hline
\end{tabular}

\begin{tabular}{|c|c|c|c|c|}
\hline Sesches/Locetas & 4 & 3 & 2 & 1 \\
\hline Gathars & 4 & 3 & 2 & 1 \\
\hline Organizes: & 4 & 3 & 2 & 1 \\
\hline Pastores & 4 & 3 & 2 & 1 \\
\hline Nevigetes & 4 & 3 & 2 & 1 \\
\hline
\end{tabular}

ADAPTATION

\begin{tabular}{l|llll}
\hline Noticos/Responds & 4 & 3 & 2 & 1 \\
\hline Accommodetes & 4 & 3 & 2 & 1 \\
\hline Actusts & 4 & 3 & 2 & 1 \\
\hline Dansfits & 4 & 3 & 2 & 1
\end{tabular}


ORGANIZES - logically positions or spatially arranges tools and materials in an orderly fashion in and between appropriate workspace(s) in order to facilitate ease of task performance.

The examiner observes the client to:

4 = readily and consistently position and spatially arrange tools and materials in a manner that supports task progression

- organizes tools and materials in a logical or effective manner

- arranges serving bowls next to salad bowl to facilitate efficient serving

- positions jelly jar close to the bread while scooping jelly onto the bread

- places folded laundry in organized piles on the table

3 = have questionable organizing skill, but with no apparent disruption of action item or task performance, or impact on other skill items

- examiner questions appropriateness of the spatial arrangement of the tools and materials within the workspace

2 = have ineffective organizing skill that impacts on action item or task performance, or results in inefficient use of time or energy

- positioning serving bowls a foot away from salad bowl requires the use of inefficient movement patterns to serve salad

- positioning of peanut butter and jelly jars requires reaching over the peanut butter to get jelly from the jelly jar

- positioning peanut butter and jelly jars on a wheelchair lapboard and the bread on an adjacent workspace (e.g., counter) results in the use of inefficient movement patterns

- the spatial arrangement of tools and materials results in difficulty locating the carrot peeler on the cutting board

- places knife, fork, and spoon to the left of the plate when setting the table

- placing piles of laundry too close together on the table interferes with task progression

1 = have severe organizing skill deficits that clearly impede action item or task performance such that the results are unacceptable, or damage or danger is imminent

- positioning related tools and materials (e.g., serving bowls, utensils, and salad bowl; or peanut butter and jelly jars) in nonadjacent workspaces (e.g., counter and table) impedes task progression

- arrangement of tools and materials results in knocking over a peanut butter jar when reaching for the jelly jar

- arrangement of tools and materials is unacceptable and markedly impedes task progression

- places materials so close together that they are knocked off the table

- simultaneous use of several workspaces, or random change in workspace results in unacceptable delay or impedes task progression

- places knifes, forks, and spoons in a pile when setting the table

- does not sort laundry into piles (see also Restores)

- examiner intervention required because severity of organizing skill deficit results in task breakdown, or imminent risk of damage or danger 


\title{
Appendix C
}

Survey of Task Choices

From the list of activities below, select six of the activities that are most familiar to you. Please circle your six choices, then indicate by the number 1 which is most familiar, 2 second, etc. Only circle tasks that are familiar, even if less than six.

\author{
SETTING A TABLE FOR 6-10 PEOPLE \\ PREPARING FRENCH TOAST AND A BEVERAGE \\ PREPARING EGGS, TOAST, AND BREWED COFFEE \\ PREPARING EGGS, MEAT, AND BREWED COFFEE \\ PREPARING AN OMELETTE, TOAST, AND BEVERAGE \\ REPOTTING A HOUSEPLANT \\ WATERING PLANTS AND PULLING OFF DEAD LEAVES
}

IRONING A SHIRT

PREPARING A FRESH FRUIT SALAD

PREPARING A GREEN SALAD

VACUUMING A LIVING ROOM, INCLUDING MOVING FURNITURE

PREPARING A TUNA OR CHICKEN SALAD SANDWICH

PREPARING A GRILLED CHEESE SANDWICH AND BEVERAGE 


\section{Appendix D}

\section{Written Directions for Familar Tasks}

\section{MAKING EGGS, TOAST, AND BEVERAGE}

\section{Materials}

eggs

presliced bread

spread (butter, margarine, jelly, or peanut butter)

salt and pepper, optional

hot or cold beverage (iced tea, coffee, milk, soda, or juice)

\section{Description}

This task involves the preparation of (a) one or two scrambled or fried eggs in a skillet on a stove, (b) two slices of toast with one spread, and (c) hot or cold beverage. The addition of salt and pepper to the eggs is optional. Two slices of presliced bread should be toasted in a standard toaster or in a toaster oven. Cutting the toast in half is optional. Serve the eggs, toast with spread, and beverage in appropriate serving dishes at a counter or table.

\section{SCRAMBLED EGG MIXTURE AND BEVERAGE}

\section{Materials}

two or three eggs

two or three of the following: cheese, onions, peppers, mushrooms, ham, precooked potatos

presliced bread

spread (butter, margarine, jelly, or peanut butter)

salt and pepper, optional

hot or cold beverage (iced tea, coffee, milk, soda, or juice)

\section{Description}

This task involves preparing a two or three scrambled egg mixture with two or three additional chopped, sliced, grated or cubed ingredients in a skillet on a stove. These ingredients should not be prechopped. Two slices of presliced bread should be toasted in a standard toaster or toaster oven. Cutting 
the toast in half is optional. Serve the eggs, toast with spread, and selected beverage in appropriate serving dishes at a counter or table.

\section{MAKING A GREEN SALAD}

Materials

lettuce

3 or 4 of the following: tomato, cucumber, green or red pepper, radishes, carrots, onions, or celery

ready made salad dressing

Description

This task involves preparing and serving two or three portions of tossed green salad with salad dressing applied. The vegetables should not be peeled or cut prior to starting the task. The salad should be made in large bowl and served, at a counter or table, in two or three individuals bowls.

\section{MAKING A FRESH FRUIT SALAD}

\section{Materials}

four different fruits (bananas, grapes, apples, pears, melon(s), citrus, or berries)

lemon or sweetner, optional

\section{Description}

This task involves preparing and serving two portions of a fresh fruit salad. The fruit should not be peeled or cut prior to starting the task. The salad chould be made in a large bowl and served in appropriate individual dishes at at counter or table.

\section{MAKING A TUNA SANDWICH}

\section{Materials}

canned tuna or chicken

celery, onion, or pickle

mayonnaise, miracle whip salad dressing, or equivalent

presliced bread 


\section{Description}

This task involves preparing a meat salad sandwich made from canned meat, one chopped ingredient (e.g., celery, onion, pickle), and mayonnaise (or equivalent). Two slices of presliced bread should be used, and the bread should not be toasted. The sandwich is to be cut in half and served on a plate at a counter or table.

\section{MAKING A GRILLED CHEESE SANDWICH}

\section{Materials}

hot or cold beverage (iced tea, milk, soda, or coffee)

presliced bread

sliced cheese

butter or margarine

\section{Description}

This task involves preparing a grilled cheese sandwich and either a hot or cold beverage, and serving them at a counter or table. The sandwich should be grilled in a frying pan or skillet. Two slices of presliced bread and presliced cheese should be used. The sandwich should be cut in half and served on a plate. 


\section{Appendix E}

\section{Written Directions for Unfamilar Tasks}

\section{CHEERIOPOTATO}

\section{Materials}

raw potato

$1 / 2$ cup sugar

box of toothpicks

drinking glass

3 grapes, cherries, radishes, or olives

cheerios

\section{Description}

This task involves coating a peeled raw potato in granulated sugar and placing it on a glass half full of water. The potato should have approximately 20 toothpicks sticking in it and each toothpick decorated with a cheerio or the round objects. Three of the toothpicks should be decorated with round objects.

\section{DARK SECRET}

\section{Materials}

plastic container

newspaper

potting soil

rice or macaroni

salt

brown grocery bag

popped popcorn

\section{Description}

This task involves filling a plastic container half full with 1 inch strips of newspaper mixed with 1 cup of popped popcorn. The newspaper mixture should be completely covered with potting soil, topped with one half (1/2) cup of rice or macaroni, and a dash of salt. The container should be placed in the bag and put in a dark place. 


\title{
3. HANG THEM
}

HIGH

\author{
Materials \\ clothes pins \\ string, yarn or \\ fishing line \\ wire hanger \\ ribbon
}

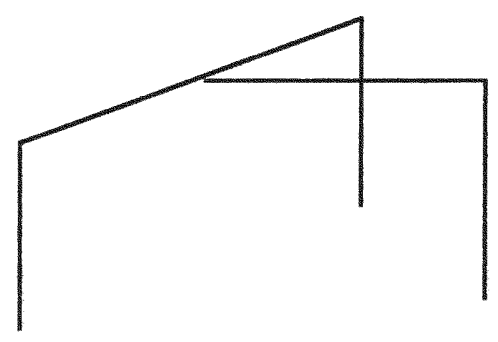

\section{Description}

This task involves hanging 6 boiled clothes pins from strings of different lengths tied to a wire coat hanger. The coat hanger should be hanging from the handle of a cabinet door or refrigerator. The six clothes pins should be boiled in water for one minute. A ribbon should decorate the hanger at the hanger's neck.

\section{CANNED TENT}

\section{Materials}

flat sheet, double or queen

two chairs with high backs

$1 / 2$ cup of flour

$31 / 2$ tablespoons of water

cans of canned goods

washcloths

\section{Description}

This task involves covering two chairs with a sheet that touches the floor. The chairs should face each other about 1 foot apart. Each corner of the sheet should be held down on the floor with a can of food placed on top of a washcloth. Two dough balls made from a flour and water mixture should be balanced on top of the sheet between the two chairs.

\section{PVC LUNCH}

\section{Materials}

carrot

string 
pvc pipe and joints

"spaghetti" string

socks

\section{Description}

This task involves constructing a three legged hanger from the pvc pipe.

The hanger should be placed on the floor or table with a sock covering the end of each leg. A peeled carrot should hang from the center joint and 4 equally spaced strands of "spaghetti" string should be hanging over each of the three leg extensions. The "spaghetti" string should be boiled in water for one minute.

\section{HOLD THAT WATER}

\section{Materials}

board with drilled holes

string or yarn

paper cup

screws

\section{Description}

This task involves placing 3 or 4 screws in each end of a board and then winding string or yarn around the screws to make a string surface strong enough to hold a paper cup full of water. The string surface should be at least 2 inches from the board. 


\section{Appendix $F$}

\section{Matrix for Scoring Skill Items}

Score Quality of
performance Impact on action progression

4

3

2

1

Competent

Supporting

Good

2

Questionable

Placing at risk

Interfering

Impeding
Outcome

yielded

$4=$ Competent performance that supports the action progression and yields good outcomes (i.e., performance that would be considered average or usual for a typical, normal young person).

$3=$ Questionable performance that places the action progression at risk and yields uncertain outcomes.

$2=$ Ineffective performance that interferes with the action progression and yields undesirable outcomes.

$1=$ Deficit performance that impedes the action progression and yields unacceptable outcomes. 


\section{VITA}

March 23, 1955

1977

1987

1991

$1987-1992$

1993-present
Born, Allentown, Pennsylvania

Bachelors of Science, Occupational Therapy

Temple University, Philadelphia, PA

Masters of Science, Health Professions Allied Health Education/Administration Southwest Texas State University, San Marcos, Texas

Masters of Science, Psychology Florida International University, Miami, Florida

Associate Professor, Department of Occupational Therapy Florida International University Miami, Florida

Assistant Professor

Department of Occupational Therapy

East Carolina University, Greenville, NC

\section{PUBLICATIONS AND PRESENTATIONS}

Dickerson, A.E. \& Fisher, A.G. (1993). Age differences in functional performance. American Journal of Occupational Therapy, 47, 686-692.

Dickerson, A.E. (1992). The relationship between affect and cognition. Occupational Therapy in Mental Health, 12 (1), 47-59.

"The Effect of Choice and Familiarity of Task on the the Functional Performance of Young and Old Adults." First International Rasch Institute, Stockholm, Sweden, October 7, 1993. 